$$
\text { د. هالة شكري عبد الفتاح نصبير ـ.أماني سعيد عبدالحمبي الخولي }
$$

\title{
إستخدام الزراع لكارت الفلاح الأكي ببعض قري محافظة الغربية
}

\author{
د. هالة شكري عبد الفتاح نصير ـ د.أماني سعيد عبدالحميد الخولي \\ معهز بحوث الإرشاد الزراعي والتنمية الريفية - مركز البحوث الزراعية دئيل
}

\begin{abstract}
المستخلص
\end{abstract}
إستهدف البحث التعرف على مستوى إستخدام منظومة كارت الفلاح الذكى بمنطقة البحث، ومستوى معرفة الزراع بأوجه الإستفادة منه، وتحديد العلاقة بين المتغيرات المستقلة المدروسة ودرجة معرفة الزراع بأوجه الإستفادة من كارت الفلاح الذكى، وكذا التعرف على أهم الطرق الإرشادية المستخدمة في توعية الزراع ونشر منظومة كارت الفلاح الذكى بينهم، وأيضاً التعرف على أهم معوقات استخدام المبحوثين لمنظومة كارت الفلاح الذكى وأهم مقترحاتهم لمواجهة تلك المعوقات، وقد أجرى البحث على عينة قوامها 226 مبحوثا تم إختيارهم عشوائياً من أربع قرى بمحافظة الغربية، وتم تجميع البيانات خلال شهر يناير 2020 بالمقابلة الشخصية بواسطة إستمارة مقابلة شخصبة بعد

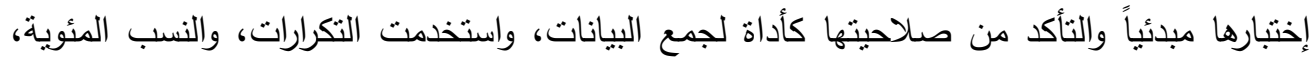
والمتوسط الحسابى، والإنحراف المعيارى، ومعامل الثبات ألفا، ومعامل الإزتباط البسيط "لبيرسون" ، وإختبار "ت" لعرض وتحليل البيانات . وقد توصل البحث إلى النتائج الآتية: 1- أن ما يقرب من ثناثة أرباع المبحوثين فأقل بأخذون حصتهم من التقاوى والسماد والمبيدات الكيماوية فى الوقت المناسب و قد إستخدموا كارت الفلاح الذكى فى تسويق المحاصيل ونقل الملكية الزراعية، أما باقى الإستخدامات لم تطبق فى الواقع الفعلى، كما أوضحت النتائج أن نصف المبحوثين فأقل كان مستوى إستخدامهم لكارت الفلاح الذكى متوسطاً ومتخفضاً، وأنه لا يوجد مستوى مرتفعاً للإستخدام لدى أي من المبحوثين. 2- أكدت النتائج وجود فروق معنوية بين متوسطى درجة معرفة الزراع بأوجه الإستفادة من كارت الفلاح الذكى عند تصنيفهم على أساس النوع، والمهنة الرئيسية، وحيازة المشاريع الزراعية. 3- وجود علاقة إرتباطية معنوية موجبة بين درجة معرفة الزراع بأوجه الإستفادة من كارت الفلاح الذكى وكل من: المستوى التعلنى للمبحوث، والمرونة الذهنية، والإتجاه نحو التغير، كما تبين وجود علاقة إرتباطية معنوية سالبة مع عدد سنوات الخبرة فى العمل الزراعى. 4- أكد المبحوثُون علي أن أكثر الطـرق الارشـادية أهميـة في نشـر المنظومـة هـي الندوات والإجتماعـات الإرشـادية (91.2\% )، والبـرامج التليفزيونيـة ( 62,4 \%)، والزيـارات المكتيـة (45,6\%)، وكانت المطبوعات الارشادية، والقوافل والحملات الإرشادية، والمواد الارشادية في 
الصحف والمجلات ، والخدمات الإستشارية المقدمة في القنوات الفضائية الزراعية، والبرامج الاذاعية الزراعية هي أهم الطرق الإرشادية التى أستخدم في توعيتهم ونثر منظومة كارت

$$
\text { الفلاح الذكى. }
$$

5- برى غالبية المبحوثين بنسبة (83,6 \%) أن أهم المعوقات التى تواجه منظومة كارت الفلاح

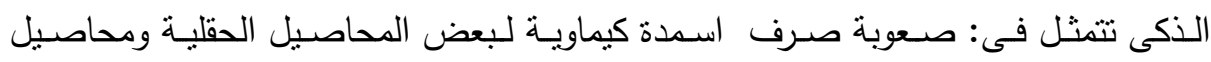

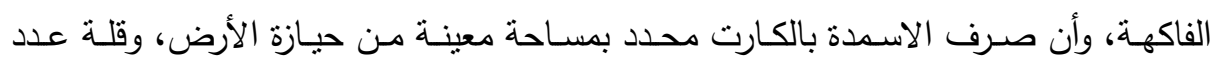

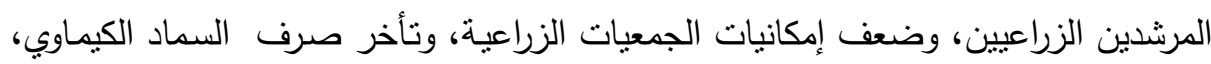

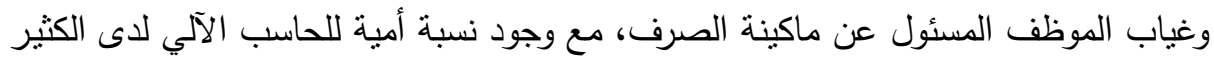

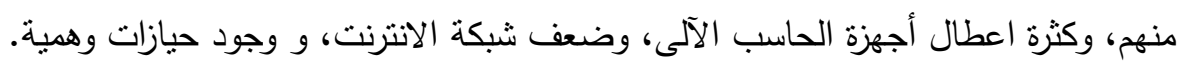

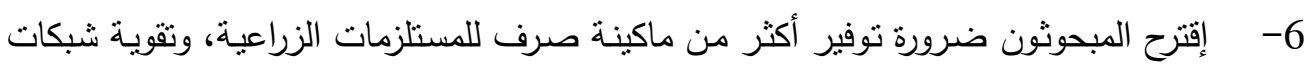

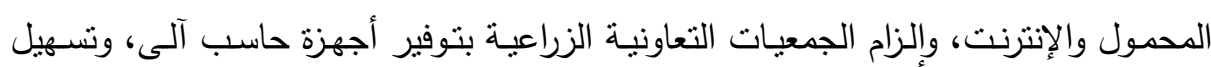
عمل بطاقة الحيازة الزراعية الإلكترونية.

\section{المقدمة والمشكلة البحثية}

شهدت الأعوام الأخيرة زيادة ملحوظة فى إستخدام وسائل التكنولوجيا الرقمية فى مجالات والماته

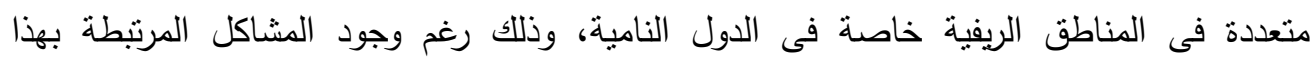

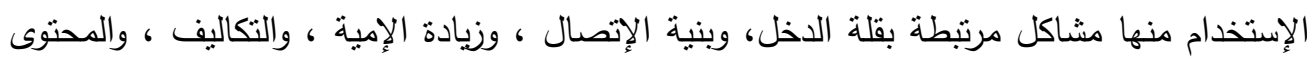

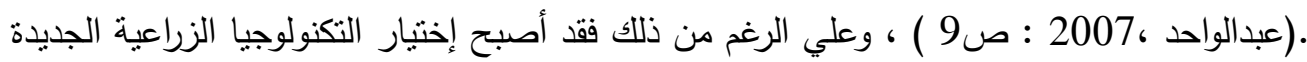

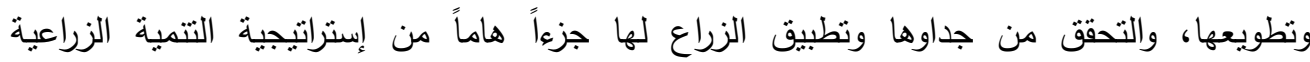
المستدامة بجمهورية مصر العربية، حيث أوضحت "إستراتيجية التتمية الزراعية المستدامة 2030 "

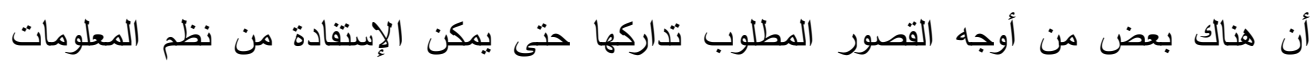

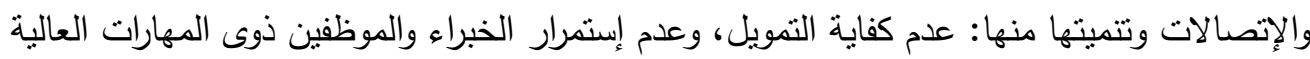

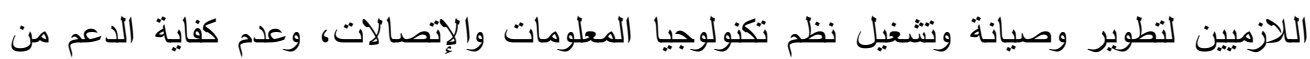

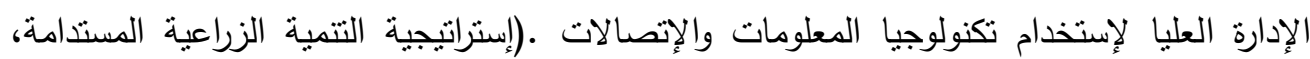

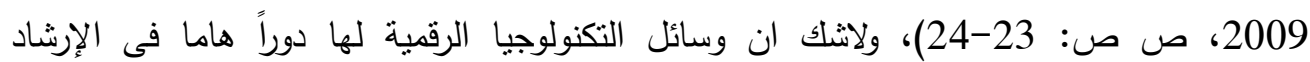
الزراعى، وتحدث تغييرات جذرية على كافة المستويات وتقلص الحواجز المكانية والزمانية بين الأفراد

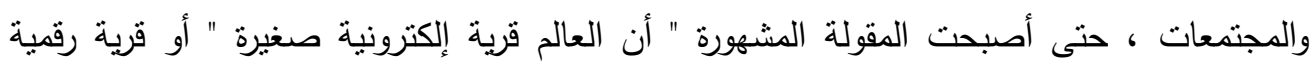

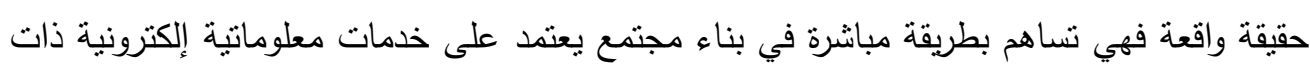
صلة مباشرة بخدمات الإتصال والإنتاج والتعليم، وتطبيق للنكنولوجيا الرقمية بإستبدال الحيازة الزراعية فئدية 


$$
\text { د. هالة شكري عبد الفتاح نصبير د.أماني سعبد عبدالحمبد الخولي }
$$

الورقية بالحيازة الاككترونية لتحسين المجتمعات الريفية وتخطي الفقر، وتخطي المراحل التقليدية للتتمية، والإنتقال إلى مسار معرفي يستتد إلى النمو، ويتمتع بقيمة مضافة أكبر من الناحية الإقتصادية (Chapman,2009 ) ) مبالتالى فإن التحول من الهيكلية التقليدية للإرشاد الزراعى في منطقة البحث والتى تعتمد علي الأداء التقليدي أصبح ضرورة للتحول إلى هيكلية شاملة التتكيل تعتمد على التقنية التى تيسر الأداء وتوفر الوقت والجهد، وذلك من خلال تخطي المراحل التقليدية للتمية والإنتقال من مرحلة حفظ المعارف إلى مبدعين فى إطار التحول الرقمي ومواكبة الثورة الرقمية، ويأتي إصدار كارت الفلاح الذكي فى إطار التعاون الدائم مع وزارة الزراعة وإستصلاح الأراضى لميكنة بطاقة الحيازة الزراعية الورقية، حيث تم توقيع بروتوكول تعاون مشترك بين البنك

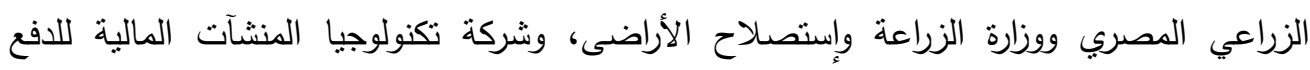
والتحصيل E-Finance، لتشغيل منظومة كارت الفلاح الذكي. وتأسيسا على ما تقدمه منظومة كارت الفلاح اليوم وهى الحلقة الواقعة على خط التماس مع العصر الرقمي لإحداث إجراءات لتحرير الأسمدة والتوصل إلى آلية مناسبة لصرف الأسمدة، مع إثراك القطاع الخاص فى أعمال التوزيع للأسمدة بجانب الجمعيات الزراعية، وأن الإستدامة التي تعني أن التحول الرقمي يوفرها أو إنها إحدى مزاياه تعني أمرين: إستدامة الموارد الطبيعية ذاتها، وإستدامة أفراد المجتمع الريفي أنفسهم وتعويض النقص الثديد فى خدمات المنظومة الزراعية من خلال إطلاق كارت الفلاح الذكي أو مايطلق عليها الحيازة الإلكترونية و بإختصار توجد العديد من العوائق التي تعرقل إستخدام هذه المنظومة منها ثقافة رفض التغيير، تلك الثقافة المبنية على الفردية والتسلسلات الهرمية فى العمل، ولا سيما من خلال تحريك القدرات والكفاءات في ظل تكنولوجيا المعلومات، وكذلك نقص الكفاءات والقدرات المتمكنة والقادرة على قيادة المنظومة والتغيير داخل العمل الزراعي كما أن نقص الميزانيات المرصودة لهذه المنظومة تحد من نموها، و يعتبر التخوف من مخاطر أمن البيانات كنتيجة لإستخدام التحول الرقمي أحد أكبر العوائق خصوصا إذا كانت الأصول ذات قيمة عالية(p59: Zazueta,2003)، ومن هنا فإن هناك ضرورة لتوفير مقومات جديدة فى العمل الزراعي من حيث مرجعيته التقليدية في الحيازات الزراعية بطريقة لا يمكن تجاهلها وكذلك الارشاد الزراعي، حيث تؤدى تقنية المعلومات الجديدة إلى أنماط جديدة من فنون احداث تغييرات سلوكية لحائزي الكارت من حيث طرق إرشادية وإستراتيجيات التفاعل والتواصل والمشاركة فى إنثاء قاعدة بيانات زراعية دقيقة تساعد في تتفيذ الإستراتيجيات وإتخاذ القرار، وتصحيح وتحسين الأوضاع القائمة على الأراضي الزراعية من الناحية القانونية، وستكون الفرصة ملائمة لتصحيح الأوضاع، حيث قررت الحكومة المصرية الإستمرار بكل جدية الدخول الي التحول الرقمي ومواكبة الثورة الرقمية والتي حولت العالم الي قرية صغيرة، والتحول الرقمي في الحيازة الزراعية هو عملية يتم 


\section{المجلة العلمية للارشاد النزاعى المجلد الرابع والعشرون العدد الرابع 2020}

من خلالها إستبدال البيانات المساحية المكتوبة بالطرق اليدوية علي الأوراق وتحويلها إلي النظام

$$
\text { الرقمي الإلكتروني عبر الإنترنت. }
$$

وفى السنوات الاخيرة بدأ الإهتمام بمفهوم أنظمة الدعرفة الزراعية ، ومع بداية الألفية

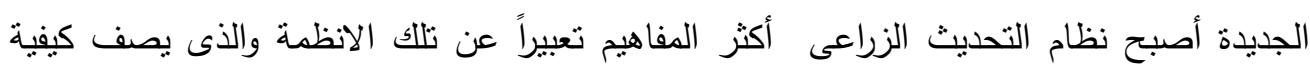
تطوير القطاع الزراعى بشكل يمكنه أن يستجيب بشكل أكبر لاحتياجات المستهدفين (سرحان ،

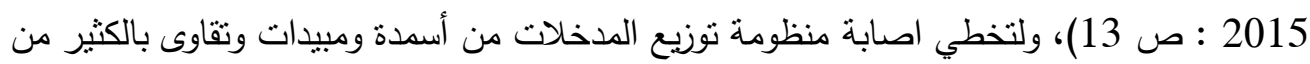

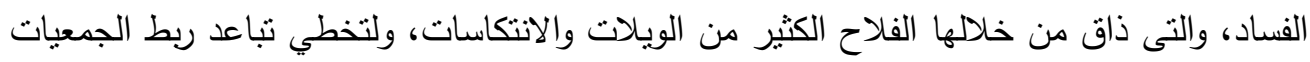

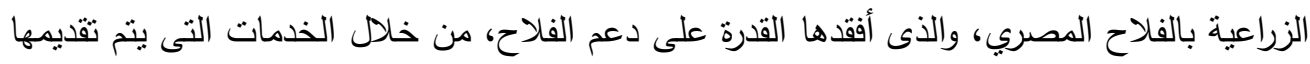

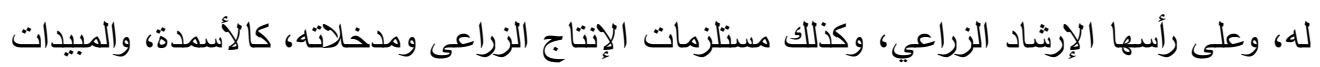

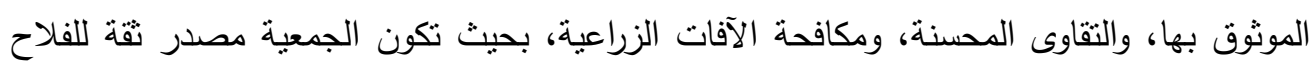
المصري، والداعم الأساسى له فى سبيل زيادة إنتاجيته وتحسين دخله فكانت الحيازة الإلكترونية أو ما

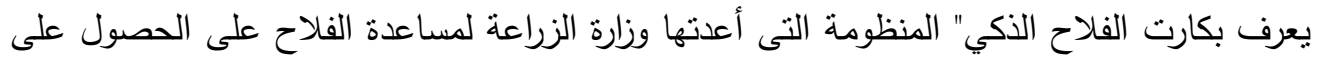
كل مستحقاته من مستلزمات الإنتاج الزراعى ومدخلاته بدون خلل ، والتسهيل عليه فى عمليات

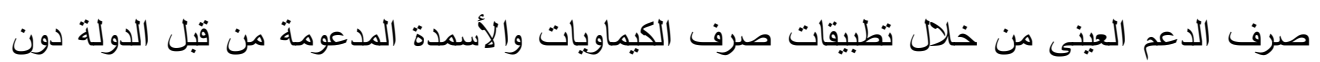

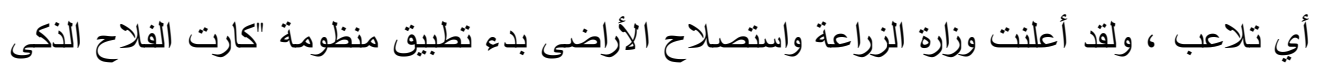

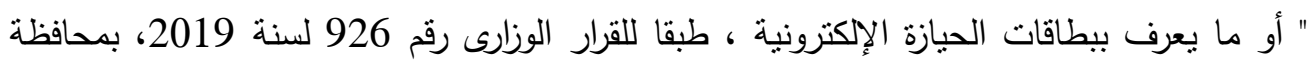

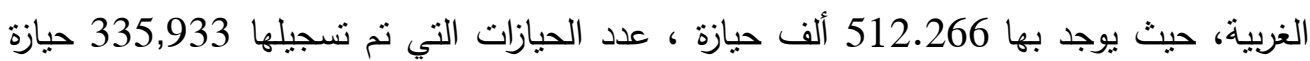

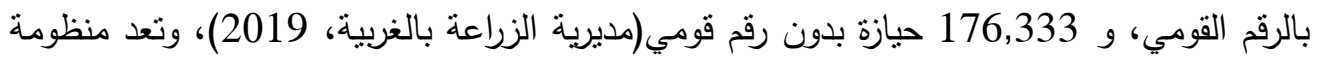

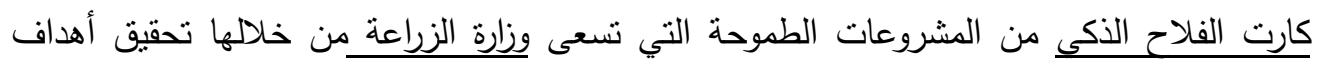

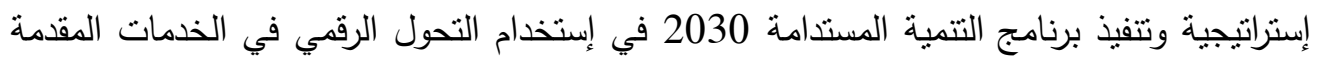
للفلاح، وأحداث تطوير للقطاع الزراعى وبناء منظومة حديثة للزراعة.

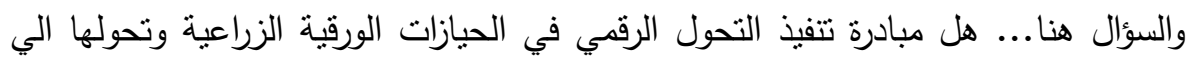

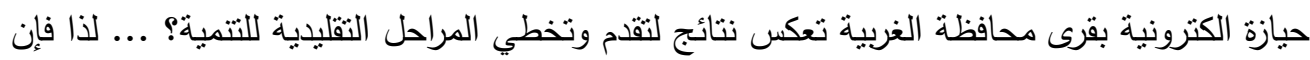
هنالك حاجة تدعو للتعرف على مستوى إستخدام تلك المنظومة للإستفادة منها، والتعرف على ألى أهم

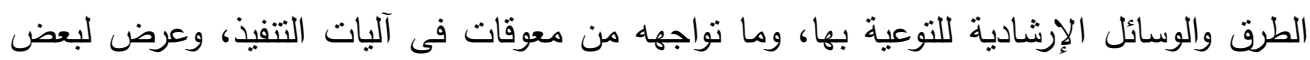

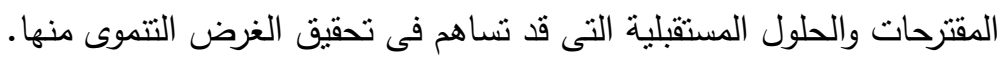




$$
\text { د. هالة شكري عبد الفتاح نصبير د.أماني سعبد عبدالحمبد الخولي }
$$

أهداف البحث

إستهدف هذا البحث بصفة رئيسية التعرف على مدي إستخدام منظومة كارت الفلاح الذكى

في بعض قرى محافظة الغربية ويمكن تحقيق هذا الهدف من خلال تحقيق الأهداف الفرعية التالية: 1- التعرف على مستوى إستخدام منظومة كارت الفلاح الذكى بمنطقة البحث.

2- التعرف على مستوى معرفة الزراع بأوجه الإستفادة من كارت الفلاح الذكى.

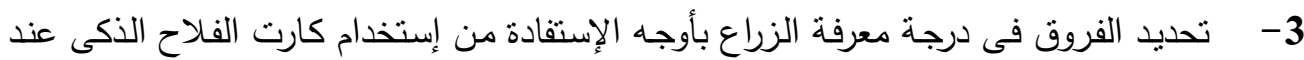

تصنيفهر على أساس النوع، المهنة الرئيسية، حيازة المشاريع الزراعية.

4- تحديد العلاقة بين المتغيرات المستقلة المدروسة ودرجة معرفة الزراع بأوجه الإستفادة لكارت

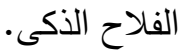

5- التعرف على أهم الطرق الإرشادية المستخدمة في توعية الزراع ونشر منظومة كارت الفلاح

الذكى.

6- التعرف على أهم معوقات استخدام المبحوثين لمنظومة كارت الفلاح الذكى ونظرة مستقبلية

لمقترحاتهم لمواجهة تلك المعوقات.

\section{الأهمية التطبيقية}

ترجع الأهمية التطبيقية لهذا البحث إلى أنه يعطي أساساً علمياً منطقياً حول منظومة الكارت الذكي للفلاح مسنمد من الواقع وتزيد من فرص معرفة الزراع بإستخدامات كارت الفلاح الذكي، وخصوصاً ان الفلاح لا يستفيد بفائدة التعويم في بيع المنتج، لأنه ليس المتعامل النهائي في عملية البيع، وقد يقلل كارت الفلاح الذكي هذه التداعيات، بالإضافة أن تللك المنظومة تعود بالنفع على الفلاح والدولة معاً، كما نوفر نتائج البحث كماً من المعلومات عن هذا المجال يهيء أساساً واقعياً لتخطيط وتتفيذ برامج تدريبية للمسئولين المتعاملين مع حائزي الكارت في منطقة البحث كخطوة مهمة في طريق الزراعة الرقمية في القطاع الزراعي، إضافة إلي تزويد المسئولين عن معوقات آلية تتفيذ منظومة كارت الفلاح الذكي من وجهة نظر هؤلاء المبحوثيين الحائزين للكارت، فى محاولة لتقديم حلول مقترحة للتغلب على المعوقات التي تحد من إستخدام كارت الفلاح الذكي، وكون هذا البحث من الدراسات الإرشادية الزراعية الأولية التي تتاولت منظومة كارت الفلاح الذكي بإعتباره مدخلاً لإحداث تغييرات مرغوبة لتحديد الإنتاج من المحاصيل وحصر الحيازات الزراعية على مستوى لإنى منطقة البحث للقضاء على الحيازات الوهمية، وضمان سهولة الحصول على قروض زراعية للمزارعين، وزيادة كفاءة أداء الجمعيات الزراعية فى التعامل مع المزارعين. 
الإستعراض المرجعي

أن التكنولوجيا technology - بمعناها الثامل - هى المعرفة والأدوات التى يؤثز بها

الإنسان فى العالم الخارجى ويسيطر بواسطتها على المادة لتحقيق النتائج العلمية والعملية المرغوب فيها ، ويهدف الإرشاد الزراعى كما يهدف غيره من الأنشطة التعليمية إلى إحداث تغييرات مرغوبة فى سلوك الأفراد، وذللك عن طريق تشكيل وتدعيم البنيان المعرفى لهم، وتغيير ما لايهم من إتجاهات سلبية غير مرغوب فيها ، وتدعيم الإتجاهات الإيجابية المرغوبة، مستخدماً فى سبيل تحقيق ذلك طرقاً ارشادية تعليمية متعددة ومتتوعة، بالاضافة إلى العديد من المعينات الإرشادية لإتاحة الفرصة للمسترشدين للتعلم من خلال العمل والممارسة، ويمكن تطبيق هذه التكنولوجيا فى المجال الصحى والتعليمى وكذللك المجال الإرشادي الزراعى الذى يعتمد على نشر المعلومات والمعارف الزراعية للمناطق الريفية لتحسين ورفع المستوى المعيثى، وزيادة الإنتاج الزراعى والمساعدة على إتخاذ القرارات المزرعية، كما نوفر قنوات إتصال واسعة بين الهيئات البحثية الزراعية ، والمنظمات التتموية الحكومية وغير الحكومية ـ (z35): Zazueta,2003)، وحيث تعتبر التكنولوجيا الرقمية أداة قوية جداً لتعليم الريفيين وإمدادهم بالمعارف والمهارات التي يحتاجون إليها في تحسين حياتهم، وكذلك تتمية مهاراتهم الثخصية، وقد أثبتت الدراسات التي قامت بها مؤسسات دولية منل منظمة الأغذية والزراعة (FAO) والبنك الدولي أن الاستثمار في مجالات التعليم، والتدريب غير الرسمي كالإرشاد الزراعي في الريف يحقق عائداً استثمارياً أعلى بكثير من عوائد استثمار التكنولوجيا الزراعية ذاتها، ومن هنا تظهر أهمية تطبيق التكنولوجيا الرقمية في قطاع الإرشاد الزراعي كأحد مجالات التتمية الريفية، حيث أصبح الاتصال حقيقة ضرورية في حياة الريفيين الحديثة، فأغلب الناس يقومون بالإتصال وتلقي، ونقل المعلومات من وإلى بعضهم البعض حتى وإن لم يكن الاتصال عملهم الأساسي .p6) (FAO 2001:p6)، ويعتبر الإرشاد الزراعى من أهم الأجهزة الإتصالية فى الريف المصرى ، حيث يقوم بعملية نقل وتوصيل نتائج البحوث العلمية والتوصيات الفنية الزراعية الصالحة للتطبيق بأسلوب مبسط ومفهوم إلى جمهور الزراع بهذف تبنيهم لها ، حيث يتصل المرشد الزراعى بهى بالزراع للتعرف على ظروفه ونقل التقنية الزراعية المستحدثة إليهم ، والتعرف على مشكلاتهم والعمل على إيجاد الحلول المناسبة لها، ولذلك فإن الجهاز الإرشادى أصبح يواجه تحديات كبيرة يلزم مواجنها والتسلح بالمعرفة لكل ما طرأ على الساحة الزراعية الاقتصادية من أفكار مستحدثة تؤثر بشكل فعال فى تطوير وتحديث جوانب الإنتاج الزراعى والخدمات.(الربيعى، 2008 : ص ص ص154-153)، وايماناً بأهمية الاستفادة من تكنولوجيا المعلومات و الاتصالات لتحقيق التتمية الثاملة ،تم تدعيم مختلف قطاعات الدولة بوسائل تكنولوجيا المعلومات و الاتصالات كمدخل مميز لزيادة قدرتها على تحقيق ما تهدف اليه لذا قامت وزارة الزراعة واستصلاح الاراضى بإنثاء العديد من 


$$
\text { د. هالة شكري عبد الفتاح نصبير د.أماني سعبد عبدالحمبد الخولي }
$$

مراكز المعلومات، ووحدات الحاسب الآلى المتخصصة فى المجالات الزراعية البحثية والإرشادية والخدمية لضمان تدفق المعلومات الزراعية الزراعية، وتوصيل الدعم العينى لمستحقينه من مستلزمات

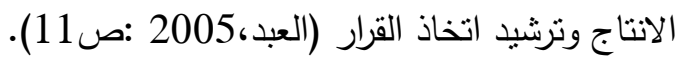

\section{الإطار النظري لمنظومة الكارت الأكي}

إن دخول وسائل التكنولوجيا الرقمية في المجتمع الريفى في منطقة البحث يعمل على رفع

كفاءة الحالة التتموية وإحداث متغيرات التتمية لدى سكانه من الريفيين، ومن هنا تأتى اهمية هذه الدراسة :حيث أن هذه الدراسة تهدف إلى تحديد واقع الإستفادة من استخدام منظومة الكارت فى عملية التتمية الريفية بمنطقة البحث، ويأني إصدار كارت الفلاح الذكي فى إطار التعاون الدائم مع مع الإنى وزارة الزراعة وإستصلاح الأراضى لميكنة بطاقة الحيازة الزراعية الورقية، حيث نم توقيع بروتوكول تعاون مشترك بين البنك الزراعي المصري، ووزارة الزراعة وإستصلاح الأراضى، وشركة تكنولوجيا المنشآت المالية للدفع والتحصيل E-Finance، لتشغيل منظومة كارت الفلاح الذكي، حيث يساهم المشروع فى إتاحة صرف مستلزمات الإنتاج عن طريق البطاقة الذكية من تقاوى وأسمدة ومواد بترولية ومبيدات وخدمات زراعية، كما يساعد فى إتاحة كافة التقارير لدعم اتخاذ القرار والتقارير الرقابية والإحصائية والمساحات المنزرعة من كل محصول على مستوى الدولة، وحصر وميكنة مساحات المحاصيل المنزرعة فى المواسم الزراعية المختلفة، وميكنة الجمعيات الزراعية وتأهيل وتدريب العاملين بالجمعيات على الاستفادة من وسائل التكنولوجيا الحديثة واستخدامها، وأوضح تقرير صادر عن وزارة الزراعة أن الهدف من نشغيل المنظومة توفير قاعدة بيانات قومية بكافة حيازات الأراضي الزراعية، ووصول الدعم لمستحقيه من المزارعين، ويسمح للحكومة بتدقيق الزمام وعدم التعدي على الأراضي الزراعية، ويساعد في تحديد دقيق للمساحات والمحاصيل المنزرعة وأنواعها، وصرف الدعم النقدى المشروط لحائزى الأراضى الزراعية، والملتزمين بتطبيق السياسة الزراعية للاولة، وصرف الوقود اللزم لزراعة الاراضى الحائز عليها الفلاح من محطات الوقود من خلال المنظومة الاككترونية لتوزيع المنتجات البترولية، وصرف الدعم العينى من خلال تطبيقات صرف الكيماويات والاسمدة المدعومة من قبل الدولة، ووقف التلاعب بكميات الأسمدة

\section{.(https://www.youm7.com/Tags/Index?id=379864\&tag)}

وأصدرت وزارة الزراعة ممثلة في إدارة شُئون المديريات تقريرا عن مزايا كارت الفلاح وهي

كالتالي:

الحصول على معاش أو تأمين صحي للمزارع بموجب الكارت، وتيسير صرف أي مستحقات مالية للمزارعين من خلال ماكينات الصراف الآلى، وتنهيل الحصول على الحصص المقرة للمزارعين من 


\section{المجلة العلمية للاششاد الزراعى المجلد الرابع والعشرون العدد الرابع 2020}

كافة مستلزمات الانتاج ووقود الآلات الزراعية ، وصرف القروض الميسرة للفلاح، وسداد السلف كاه الزراعية الخاصة بالحيازات المصدر لها كارت الفلاح، و إمكانية استخدام الكارت كبطاقة مسبقة الدفع لخدمات الحكومة الالكترونية، وقبول الكارت على آلات نقاط البيع الطرفية للشبكة الحكومية GOV POS، وقبول التعامل مع الكارت على آلات نقاط البيع الطرفية POS ، والتوافق الكامل للكارت مع المواصفات المصرية لقبول البطاقات الذكية على شبكة المحول القومى. وتتمل إجراءات إستخراج الكارت الذكي: الذهاب إلى الجمعية الزراعية التابع لها الحيازة الزراعية، وسحب استمارة الحيازة الإككترونية بالمجان، وإحضار صورة بطاقة الرقم القومى الخاصة بالفلاح، وإحضار صورة للحائز ونتشمل كافة المعلومات التى يحوزها. (الجريدة الرسمية، العدد 9)، وقد أفادت دراسة صوفيدي وكابلووتز ( Suvedi\&Kaplowitz : 2016 ) بتعدد مزايا استخدام الإنترنت في البرامج الإرشادية وتوصيل المعارف والممارسات إلى المستهدفين بالخدمة منها : إيجاد التوازن بين قيود ميزانية الإرشاد و تقديم الخدمة بالجودة اللازمة وخاصة مع زيادة الوصول إلى أجهزة الكمبيوتر ، والإنترنت من بين السكان ذوي الاخل المنخفض، والملمين بالقراءة والكتابة، وتوفير الوقت و الجهد، وسهولة الوصول إلى المعلومات والممارسات على الإنترنت، وسهولة مراجعتها و تحديثها باستمرار، إلى جانب إمكانية تحميلها على اسطوانات توزيعها على الجمهور المستهدف، كما أثنارت الدراسة إلى ضرورة أن يكون العاملين بالإرشاد مستعدين لإستخدام موارد الإنتاج الإعلامي المحلي، وآلية توصبل المعلومة على شبكة الإنترنت، ونظام جمع البيانات عبر الإنترنت، في حين بينت عدد من الدراسات بعض جوانب تطبيقات تكنولوجيا المعلومات والاتصالات في العمل الإرشادي ومعوقات إستخدامها ومنها دراسة ملوك وهشال (2016) والتي أظهرت أن أهم معوقات تطبيقات تكنولوجيا المعلومات والإتصالات كانت متمنلة في : المعوقات المتعلقة ببيئة العمل، ثم المتعلقة بالإنترنت، وأخيراً المتعلقة بالحاسب الآلي، وكانت أهم المعوقات المتعلقة ببيئة العمل وفقا لأهميتها من وجهة نظر العاملين بالإرشاد الزراعي المبحوثين هي: عدم ربط غالبية الإدارات الزراعية بالإنترنت، ونقص

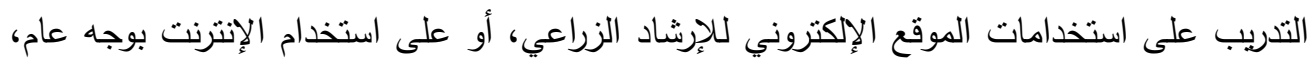
وعدم توفر المخصصات المالية لتوفير الخدمات الإككترونية بالإدارات الإرشادية الزراعية، بينما تمنلت أهم المعوقات المتعلقه بالإنترنت في: عدم توفير خدمات الإنترنت اللاسلكي(وايفاي)، وبطئ لإني سرعة الانترنت بمكان عمل المرشدين الزراعين، وانقطاعه بإستمرار، وعدم وجود تلبفون محمول حديث للاتصال بالإنترنت. في حين كانت أهم المعوقات المتعلقه بالحاسب الآلي متمثلة في: عدم لإن وجود فني لصيانة الحاسب الآلي بالإدارات الإرشادية، وعدم تزويد أجهزة الحاسب الآلي بكاميرات مشاهدة، وعدم تحديث أجهزة الحاسب الآلي بإستمرار . 
كما بينت دراسة أوكيكي وآخرون (Okeke\& et al, 2015) أن أهم المشاكل في استخدام

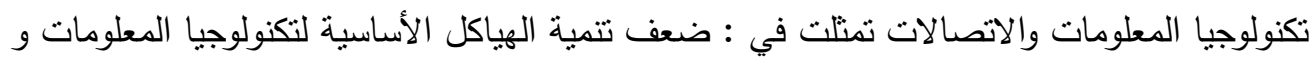

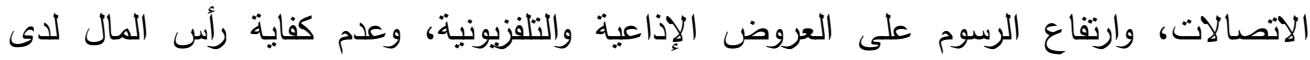

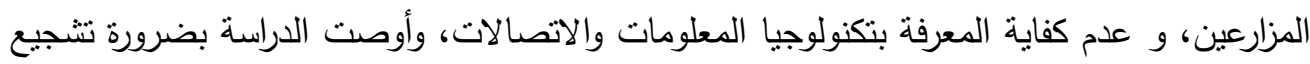

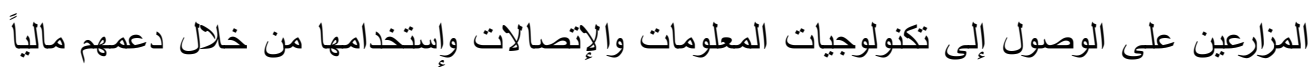

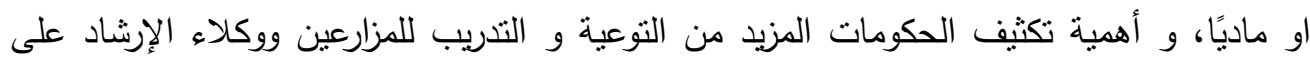
الاستخدام الفعال لمرافق تكنولوجيا المعلومات و الاتصالات .

\section{الطريقة البحثية}

منهج البحث: إعتمد البحث الراهن على المنهج الوصفى لكونه بعتمد على تجميع الحقائق

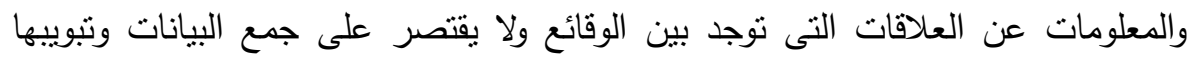

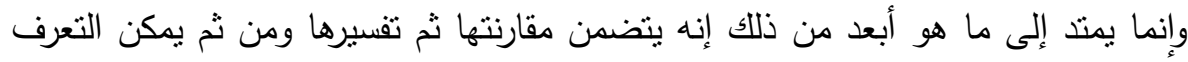

$$
\text { على الوضع الراهن لإستخدام الحيازة الإلكترونية. }
$$

حدود البحث: يقصد به ذلك الإطار الذي تجري فيه الدراسة وعلى هذا الأساس يشتمل مجال الدراسة

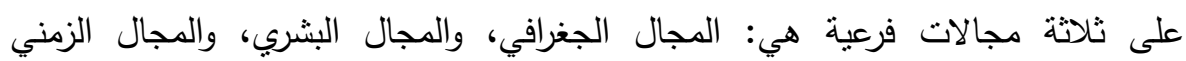
للاراسة.

أ- المجال الجغرافي: لقد تحدد النطاق الجغرافي للبحث في محافظة الغربية ، وذلك على أساس أنها

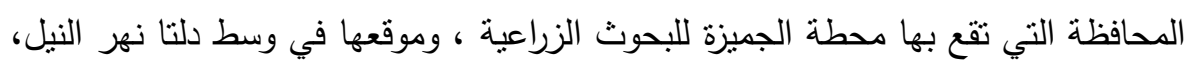

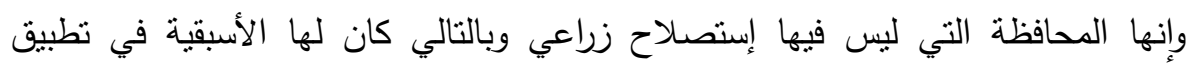
منظومة كارت الفلاح الذكي في 385 جمعية تعاونية زراعية( 44 جمعية إصلاح

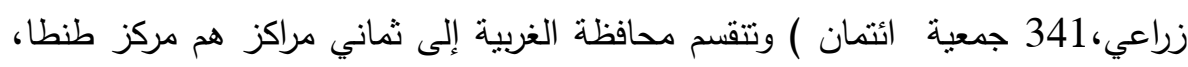
ومركز المحلة الكبرى، ومركز كفر الزيات، ومركز بسيون، ومركز قطور ، ومركز سمنود،

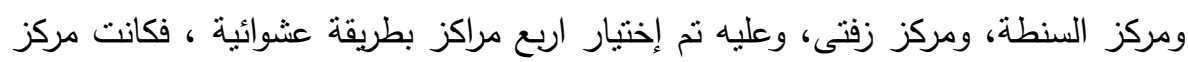

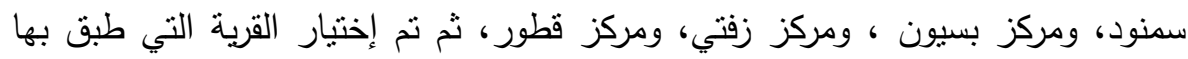

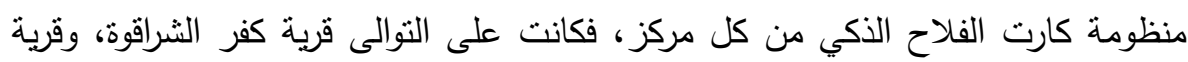

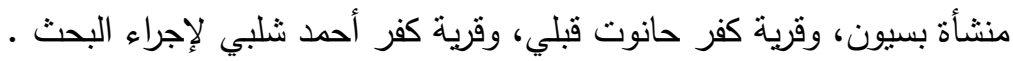

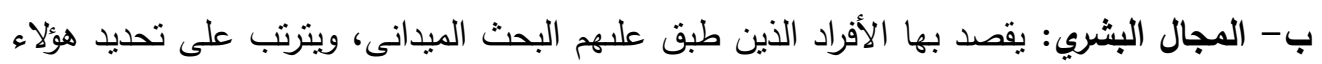

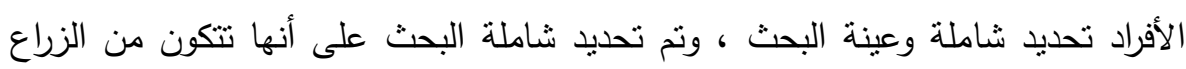

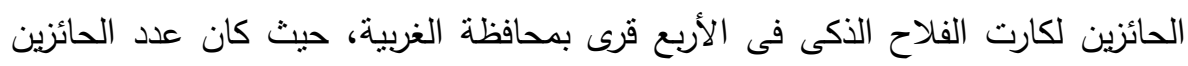


على الكارت في القرى كالأتى: قرية كفر الثراقوة 191 مزارع، قرية منشأة بسيون 164

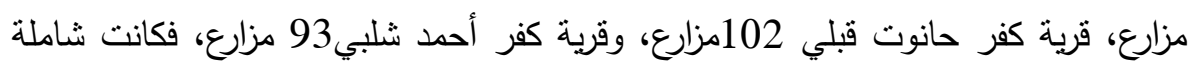
البحث 550 مزارع من الحائزين على كارت الفلاح الذكى، وطبقاً لجدول مورجان فإن العينة

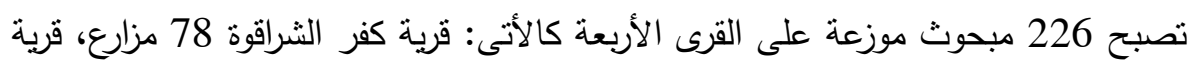

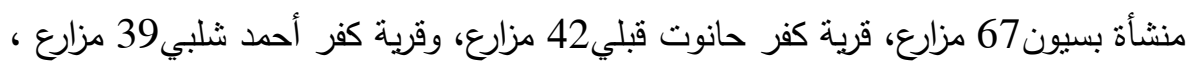
ويوضح جدول (1) توزيع شاملة وعينة البحث وفقاً لجدول مورجان لتحديد حجم العينة.

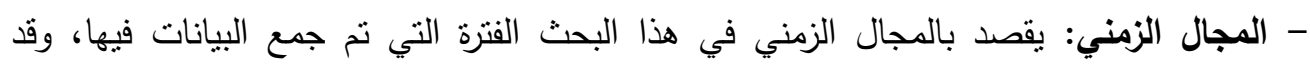

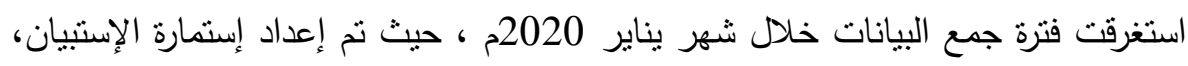

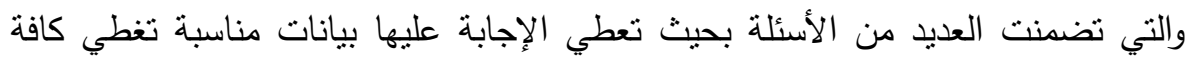

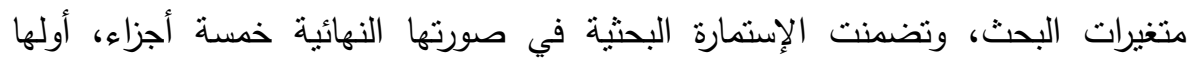

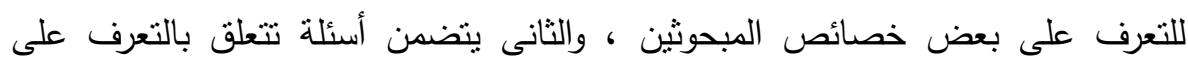

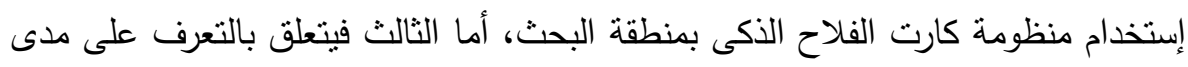

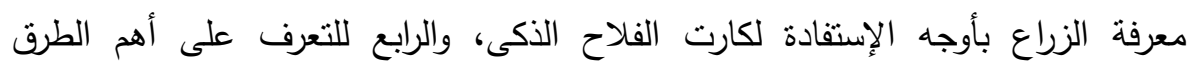

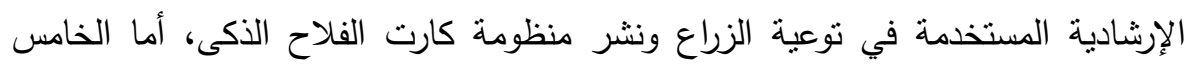

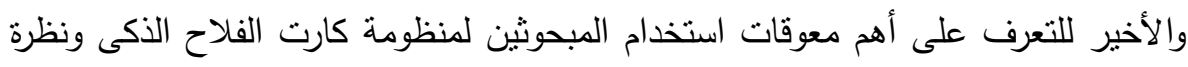

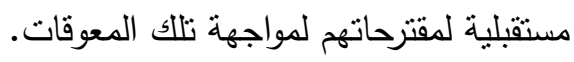

\section{التعريف الاجرائي}

- كارت الفلاح الذكى أو ما يطلق عليه الحيازة الاكترونية : يقصد به فى هذا البحث التحول

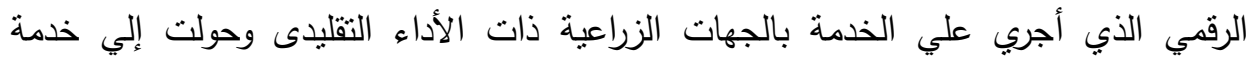

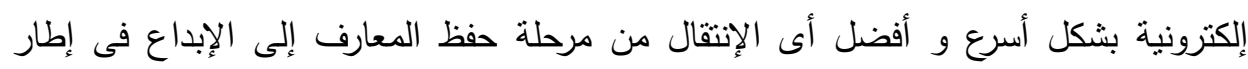

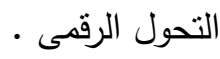

- - استخدام الكارت الأكى: يقصد به فى هذا البحث أن الخدمة المقدمة من الجمعيات التعاونية

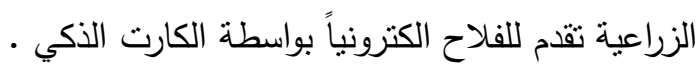

\section{قياس المتغيرات البحثية} أولاً : بعض خصائص المبورات البئة الموثين يتتاول هذا الجزء قياس المتغيرات البحثية المستخدمة في الدراسة، ويبدأ العرض بوصف طريقة قياس المتغيرات التي شملتها الدراسة، وقد تم معالجة بعض إستجابات المبحوثين لتصبح في 


$$
\text { د. هالة شكري عبد الفتاح نصبير ـ.أماني سعبد عبدالحمبد الخولي }
$$

صورة كمية يمكن من خلالها إجراء التحليلات الإحصائية لإستخلاص نتائج الدراسة، وذلك من خلال

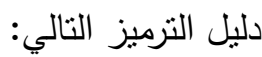

1- النوع: هو متغير من النوع الإسمى ، وقد تم تصنيفه إلى فئتين ذكر وأنثى، وأعطيت له أرقام

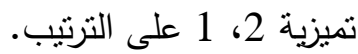

2- سـن المبحوث: تم قياس السن بإستخدام الأرقام الخـام لعمر المبحوث وقت جمع البيانات

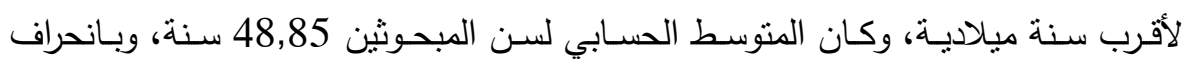

$$
\text { معياري قدره 8,475 سنة. }
$$

3- عدد سنوات التعلم: تم قياسه بعدد السنوات التى قضاها المبحوث فى التعلم حتى تاريخ جمع

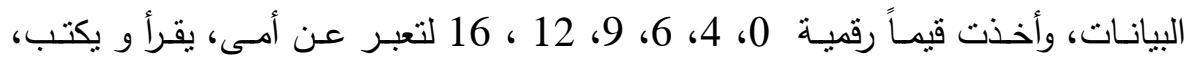
حاصل على تعلم إبتدائى، تعلم إعدادى، تعلنم متوسط، تعلنم جامعى على التزتيب.

4- المهنة الرئيسية: تم التعرف عليها بسؤال المبحوث عن مهنته الأساسية هل هى مزارع أم غير ذللك، و نم تصنيفها إلى فئتنين، وأخذت الإجابات أرقام تثيزية 2، 1 على الترنيب.

5- إجمالى الحيازة الزراعية: نم التعبير عنها بحجم المساحة الزراعية لدى المبحوث بالقيراط. 6- عدد سنوات الخبرة فى العمل الزراعى: تم قياسه بعدد السنوات التى قضاها المبحوث فى العمل الزراعى حتى تاريخ جمع البيانات.

7- حيازة المشاريع الزراعية: تم التعرف علهها بسؤال المبحوث عن حيازته للمشاريع الزراعية ، وكانت إجابته بنعم أو لا، وأخذت الإجابات أرقام تميزية 2، 1 على النرتيب.

8- الإتجاه نحو الإرشاد الزراعى: تم قياس الإتجاه نحو الإرشاد من خلال مقياس مكون من تسع

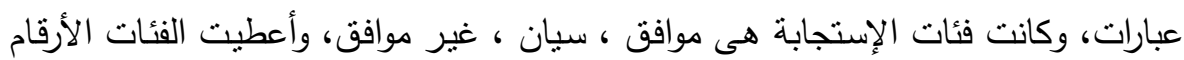

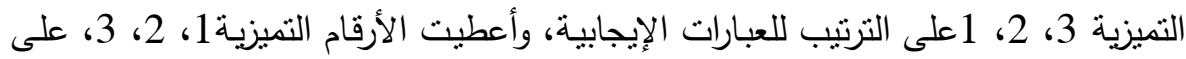
الترتيب للعبارات السلبية (الخولى، النها، 2011)، ثم قدرت درجة ثبات الدقياس بإستخدام معامل

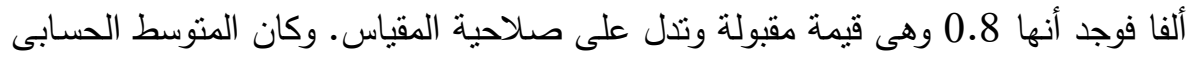
22.93، والإنحراف المعيارى قدره 3.17 درجة، وجمعت درجات البنود النسعة للحصول على الدرجة الكلية لمستوى الإتجاه نحو الإرشاد الزراعى. -9 المرونة الذهنية: تم قياس المرونة الذهنية لدى المبحوثين من خلال مقياس مكون من ثمانى عبارات، وكانت فئات الإستجابة هى موافق ، سيان ، غير موافق. وأعطيت الأرقام التميزية 


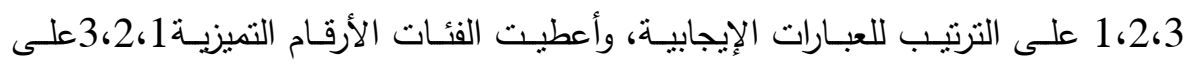

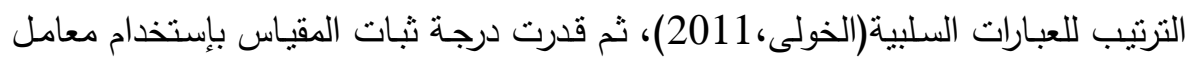

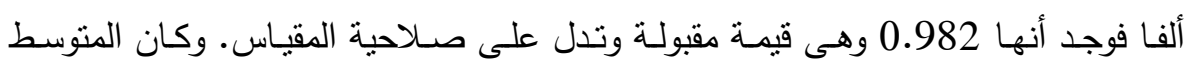

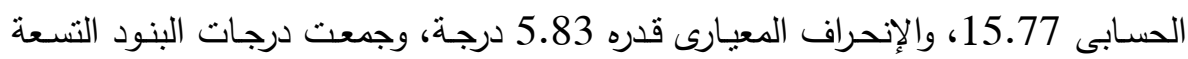
للحصول على الدرجة الكلية لمستوى المرونة الذهنية.

10- مستوى الطموح: تم قياس مستوى الطموح للمبحوثين من خلال مقياس مكون من خمسة عشر

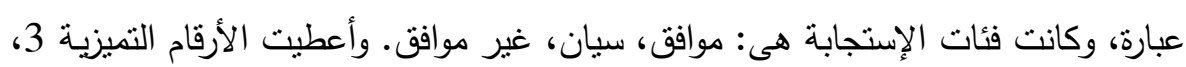

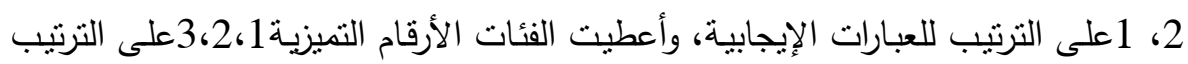

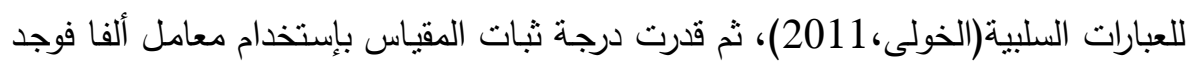

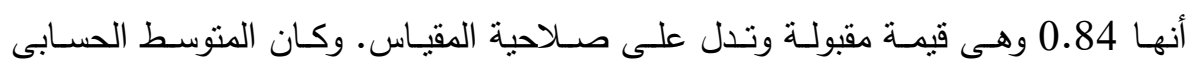

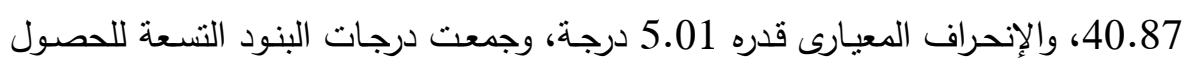
على الارجة الكلية لمستوى الطموح.

11- الإتجاه نحو التغيير: وتم قياس الإتجاه نحو التغيير من خلال مقياس مكون من أحدى عشر

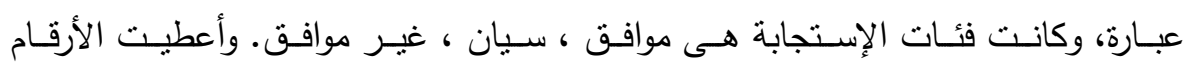

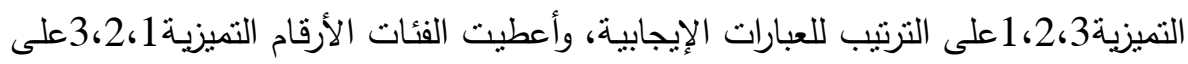

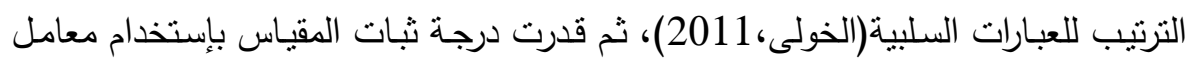

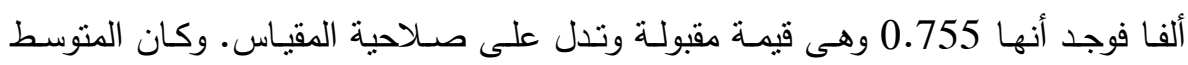

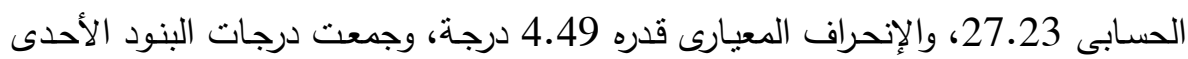
عشر للحصول على الدرجة الكلية لمستوى الإتجاه نحو التغير .

ثانياً: التعرف على مستوى إستخدام منظومة كارت الفلاح الذكى بمنطقة البحث : تم التعرف على

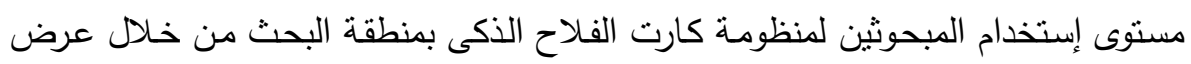

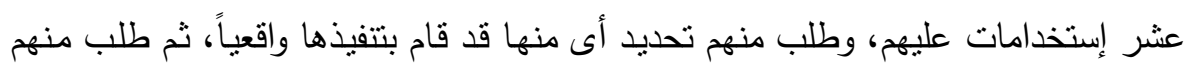

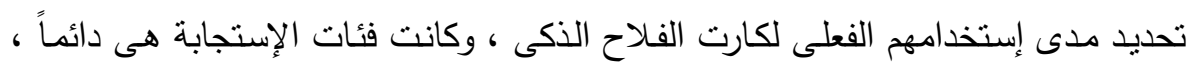

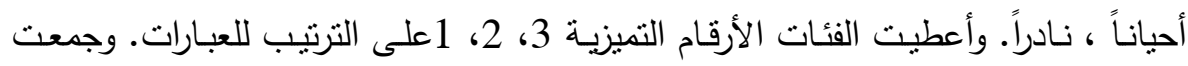
درجات الإستخدام العشر للحصول على الدرجة الكلية لمستوى واقع إستخدام منظومة كارت

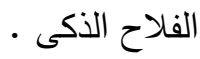




$$
\text { د. هالة شكري عبد الفتاح نصبير ـ.أماني سعيد عبدالحمبي الخولي }
$$

ثالثاً: مستوى معرفة الزراع بأوجه الإستفادة من كارت الفلاح الأكى: تم التعرف على مستوى معرفة الزراع بأوجه الإستفادة لكارت الفلاح الذكى بمنطقة البحث من خلال عرض ستة وعشرون إستفادة عليهم، وطلب منهم تحديد ما إذا كانوا يعرفونها أم لا، وكانت فئات الإستجابة هى على لإنه

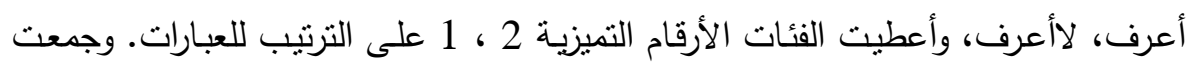
درجات الإستجابات للحصول على الدرجة الكلية لمستوى معرفة الزراع بأوجه الإستفادة من

$$
\text { كارت الفلاح الذكى. }
$$

لابعاً: التعرف على الطرق والوسائل الارشادية المستخدمة لتوعية المبحوثين ونشر منظومـة كارت الفلاح الأكى. تم التعرف على الطرق والوسائل المستخدمة فى توعية ونشر منظومة كارت الفلاح الذكى فىى رأى المبحوثين من خـلال عرض خمسـة عشر طريقة، وبسؤالهم عن مـا هي أفضل الطرق والوسائل التي تساعد في التوعية بمنظومة الكارت الذكى، والمساهمة فى نشرها. ثم رصدت الإجابات و تم عمل التكرارت لها.

خامساً: التعرف على أهم معوقات استخدام المبحوثين لمنظومة كارت الفلاح الأكى ونظرة مستقبلية لمقترحساتهم لمواجهـة تلـك المعوقـات: تم التعرف على أهم معوقات استخدام المبحوثين لمنظومة كارت الفلاح الذكى من خلال توجيه سؤال: ماهى أهم معوقات استخدام منظومة كارت الفلاح الذكى من وجهة نظرك؟ ، كما تم التعرف على الحلول المقترحة من وجهة نظرهم بسؤالهم: ما هى الحلول المقترحة من وجهة نظرك لمواجهة تلك المعوقات؟. ورصدت الإجابات و تم عمل التكرارت لها.

أساليب التحليل الإحصائى: نم إستخدام التكرارات العددية والنسب المئوية والمتوسط الحسابى، لوصف البيانات، ومعامل التبات "ألفا" للحكم على درجة ثبات المقاييس، ومعامل الإرتباط البسيط "لبيرسون" ، وإختبار (ت) لتحديد العلاقات بين متغيرات البحث.

الفـروض البحثيـة: فـى ضـوء مـا كثـفت عنـه نتائج الدراسـات السـابقة، وبنـاءاً على الإسـتعراض المرجعى، ووفق أهداف البحث الحالية، نم صياغة الفروض البحثية بما يتتاسب وطبيعة كل هدف، ولتحقيق الهدف الثالث والرابع للبحث، تم صياغة الفروض البحثية الآتية: القرض النظرى الأول: " توجد فروق معنوية بين متوسطى درجة معرفة المبحوثين بأوجه الإستفادة من

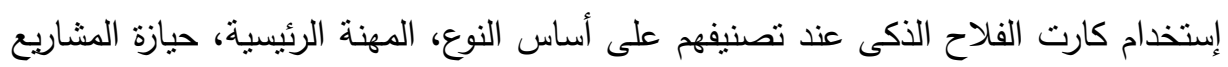


الفرض النظرى الثانى: "توجد علاقة إرتباطية معنوية بين درجة معرفة المبحوثين بأوجه الإستفادة من

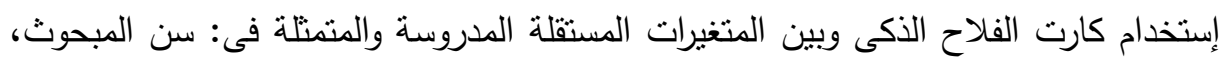

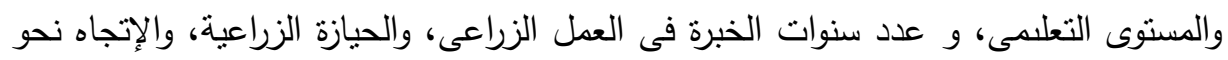

الإرشاد، والمرونة الذهنية، ومستوى الطموح، والإتجاه نحو التغير ".

\section{هذا وتم إختبار هذه الفروض في صورتها الصفرية.}

وصف خصائص المبحوثين

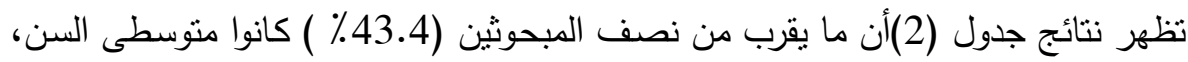

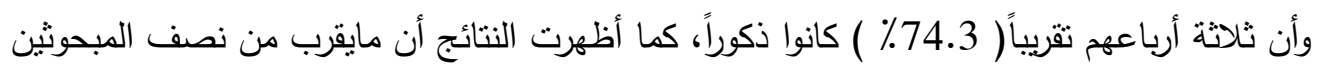

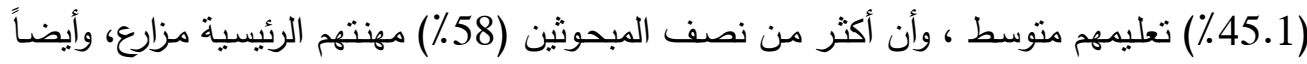

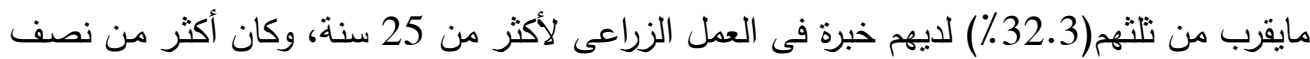

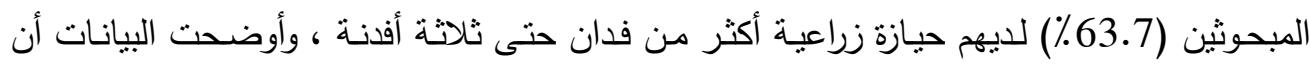

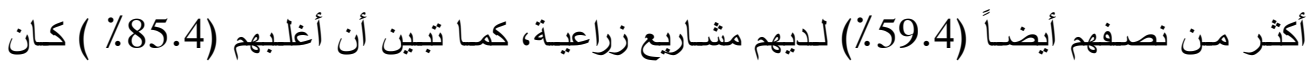

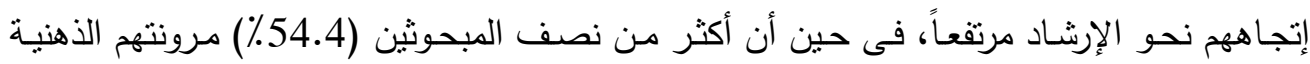

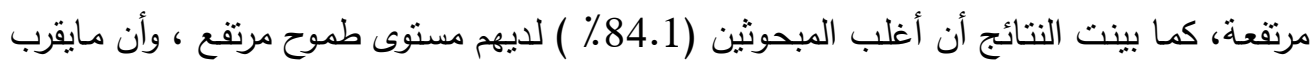
من ثلثى المبحوثين( 66.4\%) إتجهاهم نحو التغيير كان مرتفعاً.

\section{النتائج البحثية ومناقشتها}

أولاً: التعرف على مجالات إستخلام الزراع لمنظومة كارت الفلاح الذكى بمنطقة البحث

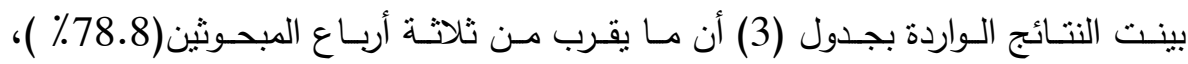

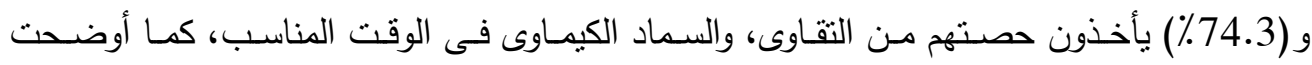

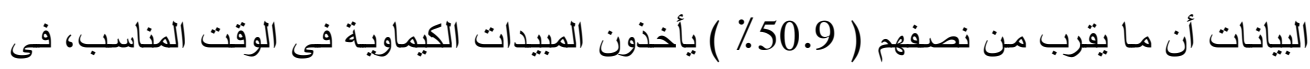

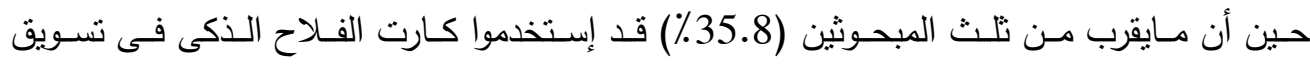

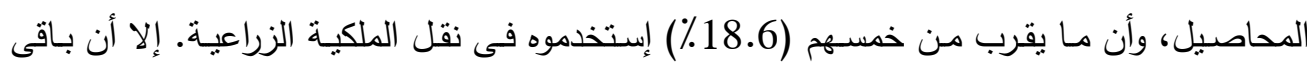

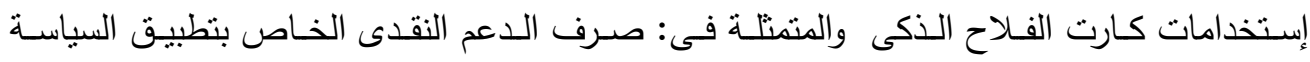

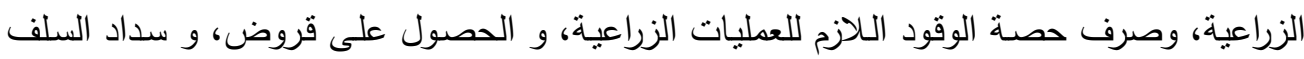

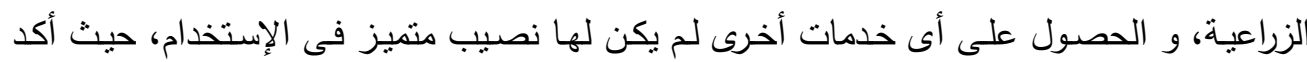

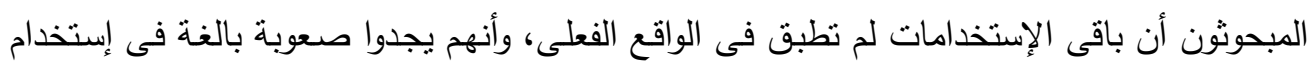

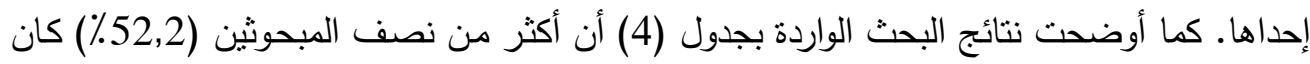

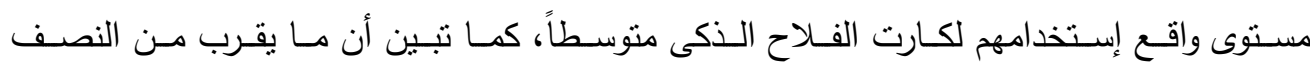




$$
\text { د. هالة شكري عبد الفتاح نصبير ـ.أماني سعيد عبدالحمبي الخولي }
$$

الأخر (47,8\%) كان مستوى واقع إستخدامهم لكارت الفلاح الذكى منخفضاً ، وجدير بالذكر أنه لا يوجد مستوى مرتفعاً لواقع إستخدامهم لكارت الفلاح الذكى لدى أي من المبحوثين . وعليه يجب مراجعة آليات تتفيذ المنظومة ، للوقوف على أهم المعوقات التى تحول دون

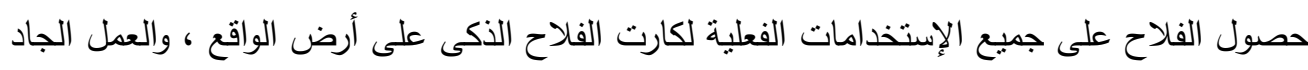
على تذليلها فى أسرع وقت لضمان نجاح المنظومة فى تحقيق أهدافها التتموية.

\section{ثانياً: التعرف على مستوى معرفة الزراع بأوجه الإستفادة لكارت الفلاح الأكى الفى}

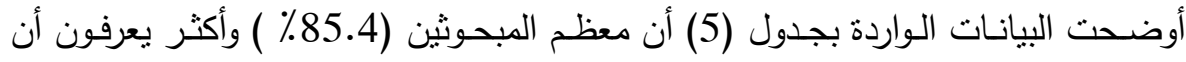
تنفيذ منظومة كارت الفلاح الذكى تؤدى إلى سهولة تقديم الخدمات الزراعية ، وتقضى على الحيازات

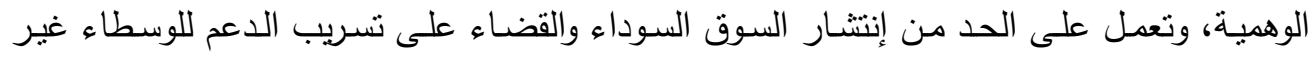
المستحقين، مـع إحكام الرقابـة على الجمعيات الزراعيـة، وصـرف الكيماويات الددعمة لمستحقيها.

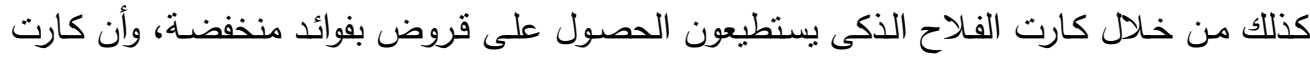

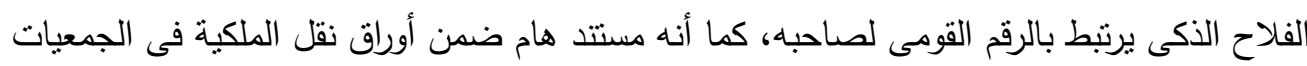

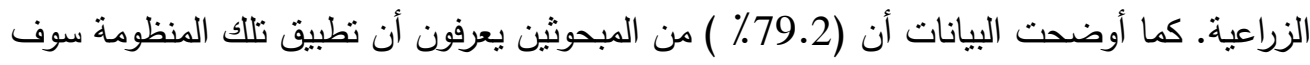

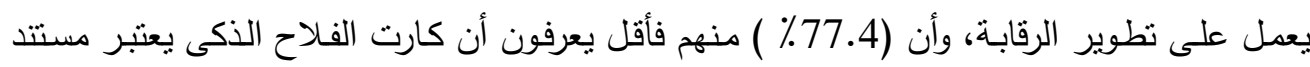

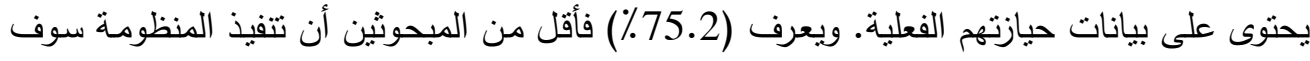

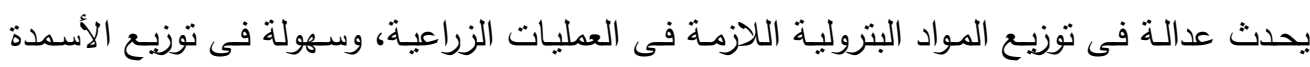

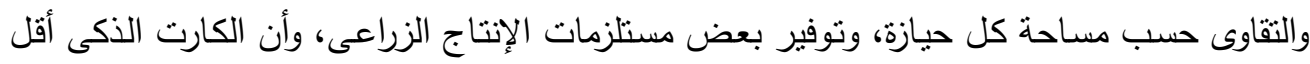

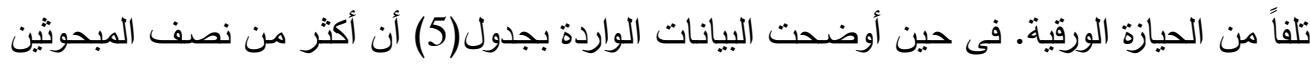

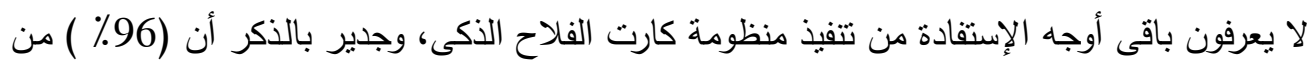

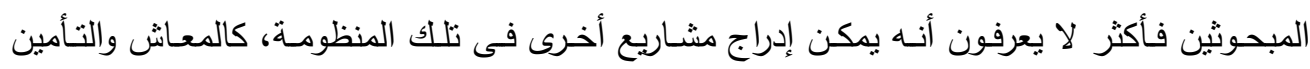

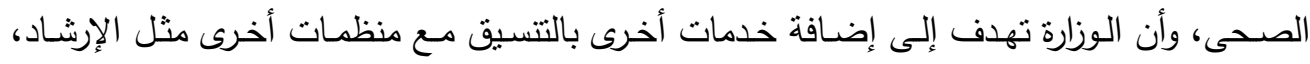

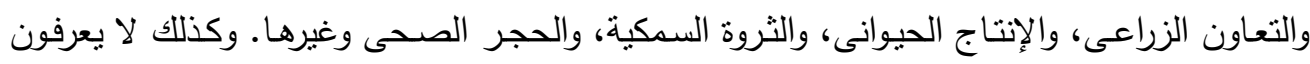

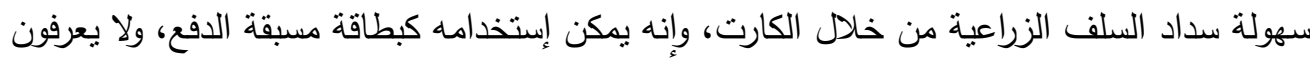

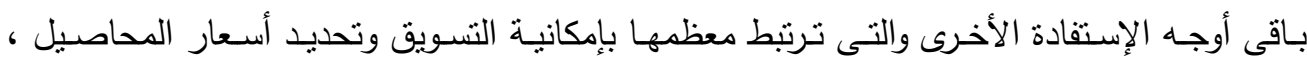
والتقدير المحصولى العام على مستوى الدولة، والتقارير الإحصائية عن المساحات الفعلية المنزرعة.

أما نتائج جدول رقم (6) فقد بينت أن( 71,2٪) من المبحوثين كان لديهم مستوى معرفة

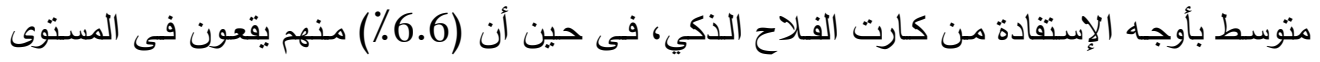


المنخفض، كما أوضحت النتائج أن أكثر من خمس المبحوثين (22.2٪) لديهم مستوى معرفة مرتفع بأوجه الإستفادة من كارت الفلاح الذكى.

وهنا يتضح أنه بالرغم من أن النتائج بينت أن غالبية المبحوثين لديهم مستوى مرتفع فى الإنى

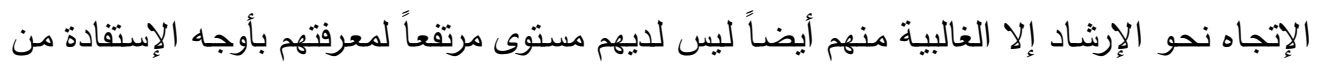

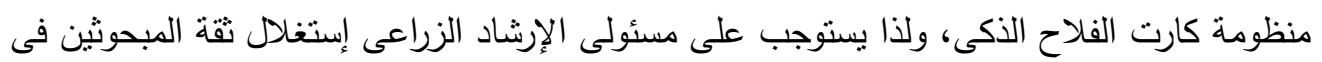

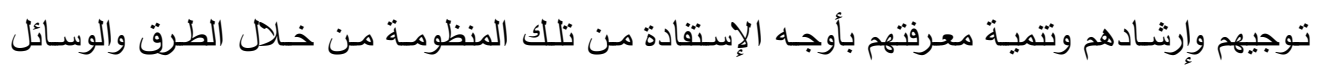
الإرشادية المختلفة.

ثالثاً: الفروق فى درجة معرفة الزراع بأوجه الإستفادة لكارت الفلاح الأكى عند تصنيفهم على الفى

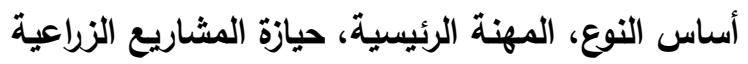
يتوقع الفرض البحثى الأول وجود فروق معنوية بين متوسطى درجة معرفة الزراعئه الزئه بأوجها

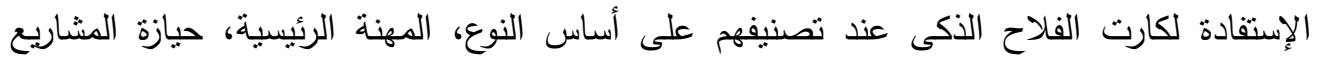

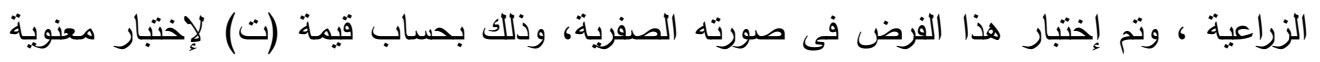

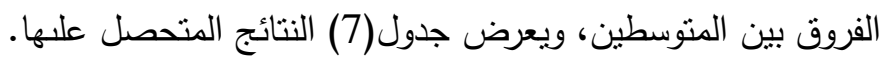

يتضح من النتائج الواردة بجدول (7) أن المتوسط الحسابى لدرجة معرفة الزراع بأوجه

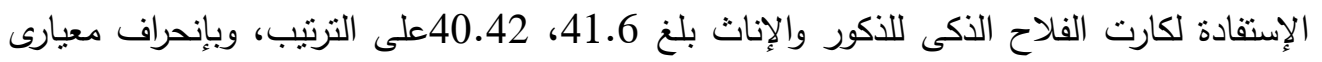

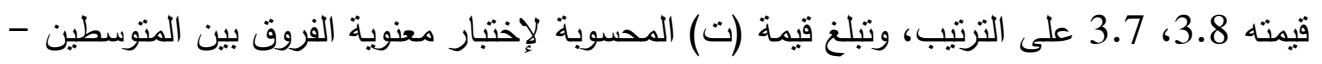

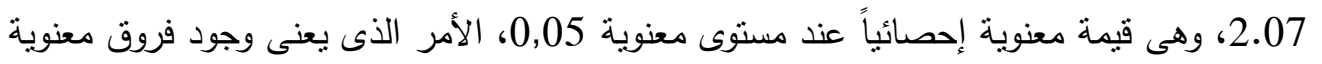

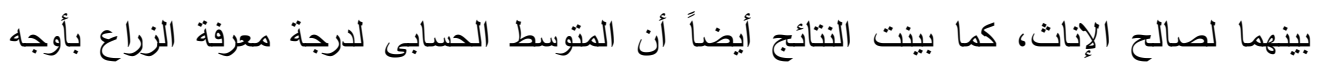

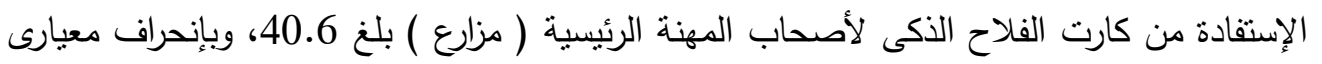

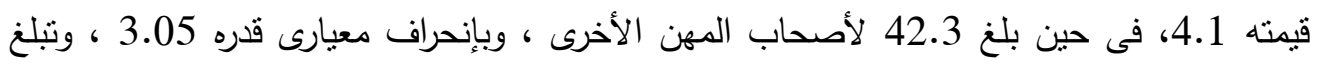

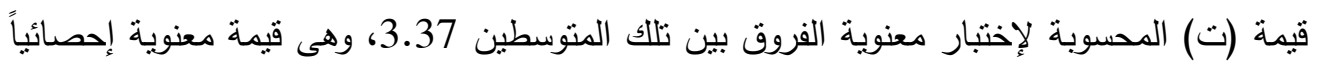

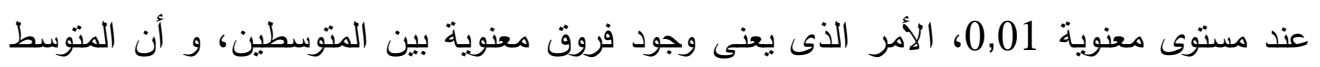

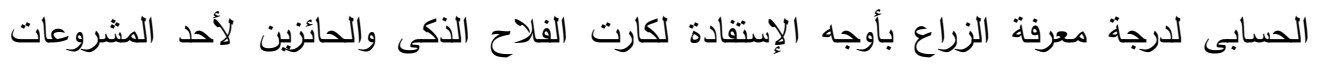

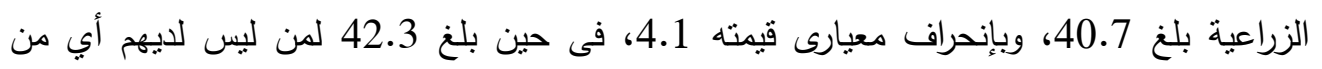

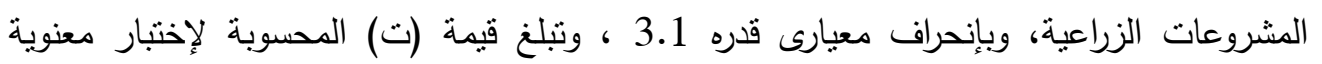

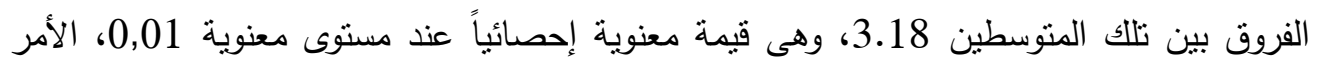

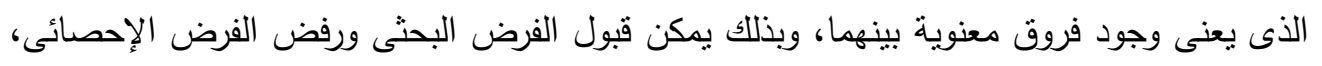




$$
\text { د. هالة شكري عبد الفتاح نصبير ـ.أماني سعيد عبدالحمبي الخولي }
$$

وجدير بالذكر أن الإناث أكثر معرفة من الذكور بأوجه الإستفادة من كارت الفلاح الذكى لذلك من الضرورى التركيز على توجيه الذكور من المزارعين للإستفادة من الخدمات التى يقدمها الإرشاد الزراعى فى مجال التوعية بمنظومة كارت الفلاح الذكى وما لها من مميزات للفلاح وللدولة ككل، كذلك من كانت مهنتهم الرئيسية مزارع كانوا أكثر معرفة بأوجه الإستفادة من كارت الفلاح الأكى،

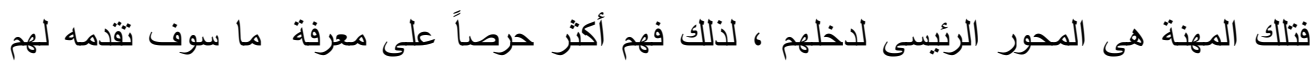
تلك المنظومة من أوجه إستفادة، حتى يتمكنوا من رفع مستوى دخولهم، كما أوضحت النتائج أن من هن لديهم مشاريع زراعية من المبحوثين كانوا أكثر معرفة بأوجه الإستفادة من كارت الفلاح الذكى. رابعاً: تحديد العلاقة بين المتغيرات المستقلة المدروسة ودرجة معرفة الزراع بأوجه الإستفادة لكارت الفلاح الأكى

يتوقع الفرض البحثى الثانى للاراسة وجود علاقة إرتباطية معنوية بين درجة معرفة المبحوثين بأوجه الإستفادة من إستخدام كارت الفلاح الأكى وبين المتغيرات المستقلة المدروسة والمتمتلة فى: سن المبحوث ، والمستوى التعليمى، وعدد سنوات الخبرة فى العمل الزراعى ، والحيازة الزراعية، والإتجاه نحو الإرشاد ، والمرونة الذهنية، ومستوى الطموح، والإتجاه نحو التغير، وقد أستخدم فى إختبار هذا الفرض معامل الإزتباط البسيط، وبوضح الجدول(8) أهم النتائج الآتية: وجود علاقة إرتباطية معنوية موجبة بين درجة معرفة الزراع بأوجه الإستفادة من كارت الفلاح الذكى وكل من: المستوى التعليمى، والمرونة الذهنية، والإتجاه نحو التغير ، حيث بلغت قيمة معامل الإرتباط بينهما 0.327، 0.251، 0.242 على الترتيب، وهى جميعها عالية المعنوية عند مستوى معنوية 0,01، كما تبين وجود علاقة إرتباطية معنوية سالبة بين درجة معرفة الزراع بأوجه الإستفادة من كارت الفلاح الذكى وعدد سنوات الخبرة فى العمل الزراعى حيث بلغت قيمة معامل الإزتباط بينهم -0.178، فى حين لم ينبين وجود علاقة بين درجة معرفة الزراع بأوجه الإستفادة لكارت الفلاح الذكى وكل من متغير: سن المبحوث ، والحيازة الزراعية، ، والإتجاه نحو الإرشاد ، ومستوى الطموح، وجدير بالذكر أنه كلما زاد كل من: المستوى التعليمى للمبحوث، والحيازة الزراعية، والمرونة الذهنية، والإتجاه نحو التغير زادت درجة معرفة الزراع بأوجه الإستفادة من كارت الفلاح الأكى ، وبذلك يمكن قبول الفرض البحثى و رفض الفرض الإحصائى جزئياً. خامساً: التعرف على أهم الوسائل والطرق الإرشادية المستخدمة في توعية الزراع ونشر منظومة كارث الفلاح الأكى 


\section{المجلة العلمية للاشاد الزراعى الدجلد اللربع والعشرون العدد الرابع 2020}

أوضحت نتائج جدول(9) أن غاليية المبحوثين 91.2\% أكدوا أن الندوات والإجتماعات

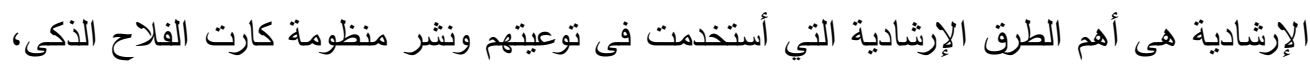

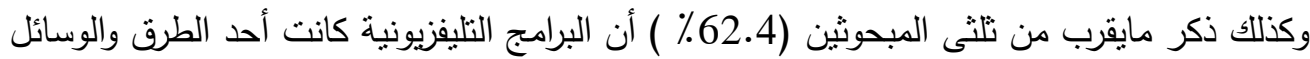
الإرشادية الهامة للتوعية ونشر منظومة كارت الفلاح الذكى، كما أكد ما يقرب من نصف المبحوثين

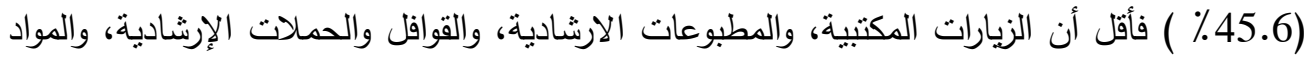
الارشادية في الصحف والمجلات، والخدمات الإستشارية المقدمة في القنوات الفضائية الزراعية،

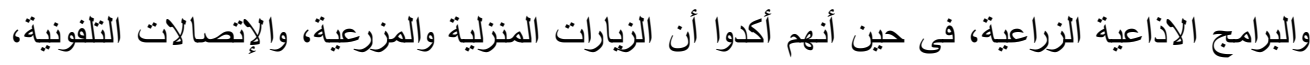

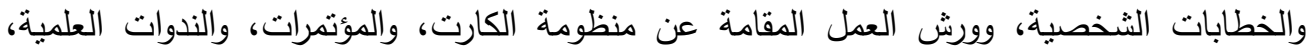

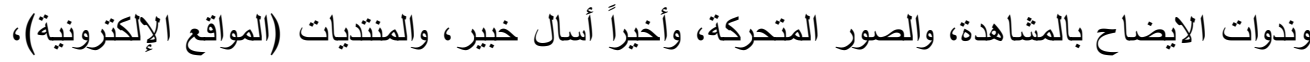
لم تكن من ضمن أهم الوسائل والطرق الإرشادية المستخدمة في توعية الزراع ونشر منظومة كارت

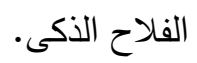

سادساً: التعرف على أهم معوقات استخدام المبحوثين لمنظومة كارت الفلاح الذكى ونظرة مستقبلية

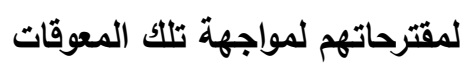

أ- - المعوقات: يتنبين من نتائج جدول(10) أن غالبية المبحوثين(83.6٪) فأكثر أكدوا أن أهم

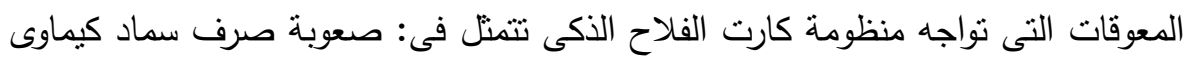
لبعض المحاصيل الحقلية ومحاصيل الفاكهة، وأن صرف الاسمدة الكيماوية بالكارت محدد بمساحة معينة من حيازة الأرض، حيث يجب أن لا تقل عن سبعة قراريط، وقلة عدد

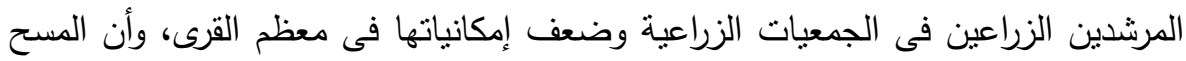
الذي يقوم به المرشد يؤخر الاسمدة الكيماوية، وغياب الموظف المسئول عن ماكينة

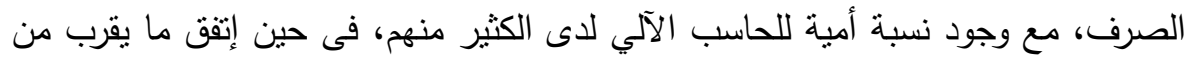

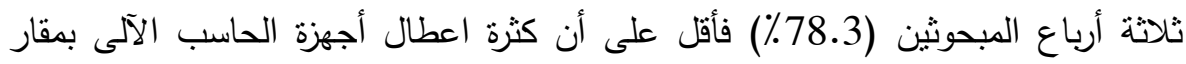

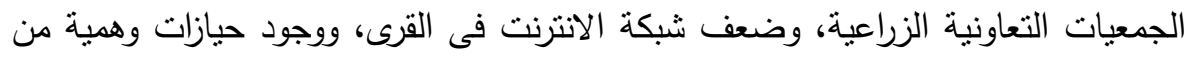

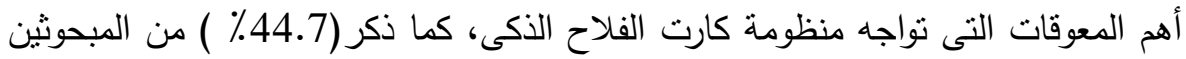

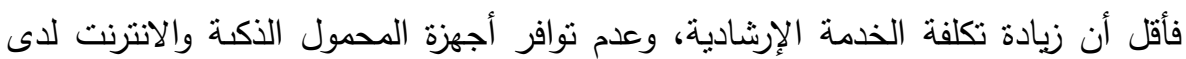

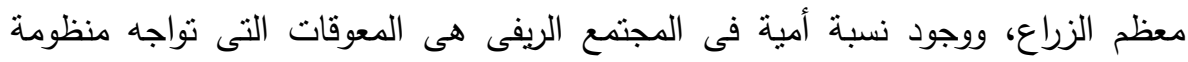

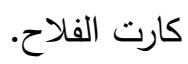
ب- - الحلول والمقترحات: ينتين من نتائج جدول(11) أن معظم المبحوثين (75.2\% ) كانت مقترحاتهم متفقة على ضرورة توفير أكثر من ماكينة صرف للمستلزمات الزراعة، وتقوية شبكات المحمول والإنترنت بالمناطق الريفية، مع إلزام الجمعيات التعاونية الزراعية بتوفير ماكئه 


$$
\text { د. هالة شكري عبد الفتاح نصبير ـ.أماني سعبد عبدالحمبد الخولي }
$$

أجهزة حاسب آلى وميكنة المعاملات مع الأعضاء، وتسهيل عمل بطاقة الحيازة الزراعية الكترونية وصرف المستلزمات بمنظومة الكترونية، وتطبيق منظومة الزراعة التعاقدية الكترونية بالكارت الذكى لتسويق المحصول، كما إقترح (69.5\%) من المبحوثين تحديث الأجهزة الإدارية بالجمعيات التعاونية الزراعية لتواكب عصر المعلومات والإتصالات والقدرة على تحديث البيانات، ورأى (64.2\%) منهم ضرورة عمل مواقع الكترونية لكل الجمعيات التعاونية الزراعية لتوثيق العلاقة بالزراع، كذلك إتفق( 55.8\%) من المبحوثين على ضرورة إتاحة نتائج البحوث الزراعية الجديدة كاملة على شبكات الانترنت حتى يستقيد منها المزارعين، كما رأى (50.4\%) منهم ضرورة عمل قواعد بيانات الكترونية تشمل الأعضاء والموارد الطبيعية والتعداد الزراعى لكل جمعية زراعية. كذلك إقترح ما يقرب من نصف المبحوثين (45.6\%) فأقل إعادة النظر فى مواصفات عضو مجلس إدارة الجمعية التعاونية الزراعية بما يواكب عصر تكنولوجيا المعلومات والاتصالات ، وتحديث عمل الجمعيات التعاونية الزراعية من خلال إنشاء شبكات ربط الكترونية، والإستعانة بشباب القرى فى إدارة نوادى لتكنولوجيا المعلومات والإتصالات بالجمعيات التعاونية الزراعية، وإعداد دورات تدريبية للقادة المحلين فى مجالات تكنولوجيا الاتصالات والتحول الرقمي، وتسهيل إجراءات التحول الرقمي للبيانات، وأخيراً عمل منتديات الكترونية لتمكين المزارعين من الحوار وتبادل الافكار والخبرات والتجارب.

التوصيات

بناءاً على النتائج السابقة يمكن إستخلاص التوصيات الآتية: لمواجهة التحديات التى تواجه إستخدام كارت الفلاح الذكي فى منطقة البحث والتى تؤثر سلباعلي الإستفادة من منظومة الحيازة الالكترونية يتطلب الأمر : الئه 1- زيادة الإنفاق علي المنظومة من حيث التطوير التكنولوجى بتوفير المسئولين في منطقة البحث

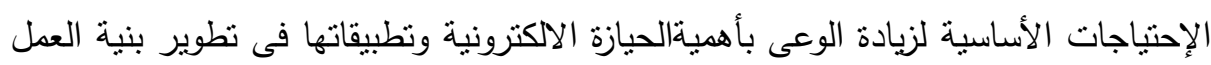
في إدارات ومديريات والجمعيات الزراعية والاستفادة من كل مجالات استخدامها. 2- توفير البنية الأساسية التى تدعم تطبيق الحيازة الالكترونية في منطقة البحث وذلك من خلال توفير المكان المناسب والمشتغلين، وتوفير التسهيلات التكنولوجية من أجهزة حاسب آلي وشبكة الإنترنت تمكن العاملين الارشاديين من ممارسة عملهم . 3- نشر الثقافة الرقمية بين القيادات الريفية والزراع في منطقة البحث، وتدريب كافة الأطراف على إستخدام كارت الفلاح والإستفادة منه، وتقديم الخدمات من خلاله. 
4- إحكام الرقابة على الجمعيات الزراعية ومديريات الزراعة للقضاء على الحيازات الوهمية، والفساد، ووصول الدعم لمستحقيه.

5- العمل على تنليل المعوقات النى تحول دون نشر وتفعيل منظومة كارت الفلاح الذكى من

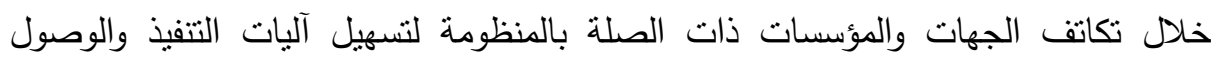
لأقصى إستفادة من تلاك المنظومة.

6- إطلاق برامج إرشادية بواسطة تطبيقات على المحمول للمساهمة فى نشر المنظومة،

$$
\text { ولتعويض النقص فى عدد المرشدين الزراعيين فى الوقت الحالى. }
$$

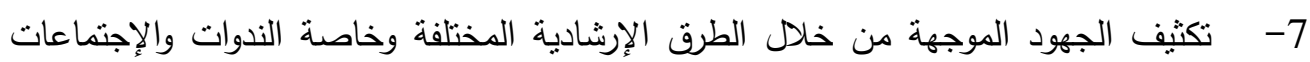

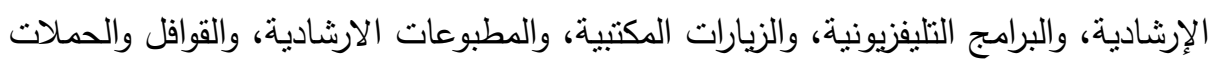
الإرشادية، والمواد الارشادية في الصحف والمجلات ، والقنوات الفضائية للتوعية بأوجه الإستفادة من تتفيذ منظومة كارت الفلاح الذكى. 8- ت تشجيع علاقات التتسيق بين الجمعيات الزراعية ومديريات الزراعة والمراكز البحثية للحصول

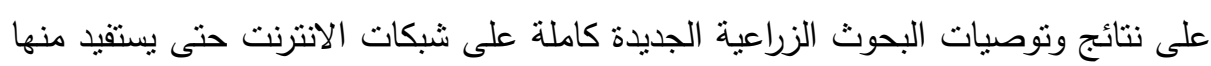

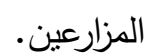

9- من الضرورى نتجيع الباحثين فى مجال الإرشاد الزراعى والتتمية الريفية على إجراء المزيد

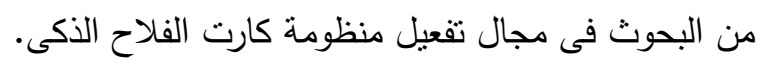

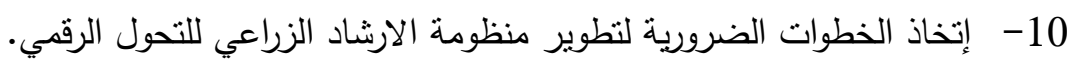

\section{الجداول}

جدول رقم 1: توزيع شاملة وعينة البحث

\begin{tabular}{|c|c|c|c|c|c|}
\hline 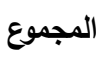 & قطور & زفتى & بسيون & سمنود & 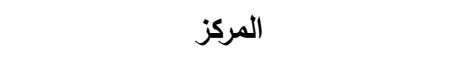 \\
\hline & كفر أحمد & كفر حانوت & منشيون & كفر الشراقوة & 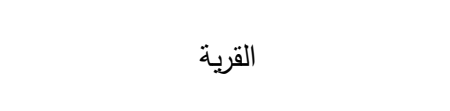 \\
\hline 550 & 93 & 102 & 164 & 191 & الزراع الحائزين على كارت الفلاح الذىى \\
\hline 226 & 39 & 42 & 67 & 78 & العينة \\
\hline
\end{tabular}

(المصدر : مديرية الزراعة بمحافظة الغربية -جدول مورجان لتحديد حجم العينة) 
جدول رقم 2: توزيع المبحوثين وفقاً لبعض الخصائص الثخصية والإجتماعية

\begin{tabular}{|c|c|c|c|c|c|c|c|c|}
\hline$\%$ & التكرار & ال المتغير & $\%$ & التكرار & 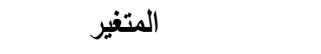 & $\%$ & التكرار & المتغير \\
\hline \multicolumn{3}{|c|}{ 8 8-مستوى الإتجاه نحو الإرشاد } & \multicolumn{3}{|c|}{ 4-المهنة الرئيسية: } & \multicolumn{3}{|c|}{ 1-السن: } \\
\hline 2.2 & 5 & منخفض (من9-أقل من15) & 58 & 131 & مزارع & 26.1 & 59 & الثباب (25-أقل من 41سنة) \\
\hline 12.4 & 28 & متوسط ( من 15-أقل من 21) & 42 & 95 & 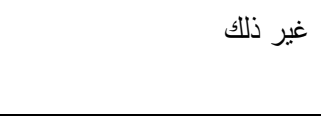 & 43.4 & 98 & 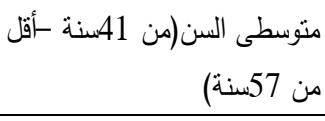 \\
\hline 85.4 & 193 & مرتقع (من 21-27) & & & 5-عدد سنوات العمل الزراعى & 30.5 & 69 & كبار السن(57-73سنة) \\
\hline \multicolumn{3}{|c|}{ 9 9-مستوى المرونة الذهنية } & 27.4 & 62 & (10) & \multicolumn{3}{|c|}{ 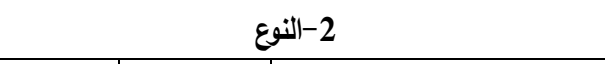 } \\
\hline 31.9 & 72 & منخفض (من7-أقل من12) & 40.3 & 91 & (أكثر من10سنوات -25سنة) & 74.3 & 168 & ذكر \\
\hline 13.7 & 31 & متوسط(من12-أقل من17) & 32.3 & 73 & (أكثر من 25سنة) & 25.7 & 58 & أنتى \\
\hline 54.4 & 123 & مرتفع(من17-21) & \multicolumn{3}{|c|}{ 6-الحيازة الزراعية: } & \multicolumn{3}{|c|}{ 3-عدد سنوات التعلم } \\
\hline \multicolumn{3}{|c|}{ 10-مستوى الطموح } & 21.7 & 49 & فدان- فأقل & 9.7 & 22 & أمى (صفر سنة) \\
\hline 0.9 & 2 & منخفض (من15-أقل من26) & 63.7 & 144 & (أكثر من فدان- 3أفدنة) & 6.6 & 15 & يقرأ ويكتب(4سنوات) \\
\hline 15 & 34 & منوسط(من26-أقل من36) & 14.6 & 33 & (أكثر من 3 فدان) & 20.8 & 47 & إعدادى(9سنوات) \\
\hline 84.1 & 190 & مرتفع(من36- 45) م & \multicolumn{3}{|c|}{ 7 الميازة المشاريع الزراعية: } & 45.1 & 102 & متوسط دبلوم فنى (12سنة) \\
\hline \multicolumn{3}{|c|}{ إلمستوى الإتجاه نحو التعير } & 59.3 & 134 & بوجد & 17.7 & 40 & جامعى(16سنة) \\
\hline 2.2 & 5 & منخفض (من11-أقل من19) & 40.7 & 92 & ل الا يوجد & & & \\
\hline 31.4 & 71 & منوسط(من19-أقل من26) & & & & & & \\
\hline 66.4 & 150 & مرتقع (من26-33) & & & & & & \\
\hline
\end{tabular}


جدول رقم 3: التوزيع العددى والنسبى للمبحوثين وفقاً لمجالات إستخدامهم لكارت الفلاح الأكى

\begin{tabular}{|c|c|c|}
\hline 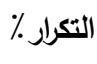 & 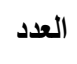 & مجالات إستخدام الفلاح لكارت الفلاح الذكى \\
\hline$\% 78.8$ & 178 & 1-بتاخد حصتلك من التقاوى في الوقت المناسب. \\
\hline$\% 74.3$ & 168 & 2-بتاخد السماد الكيماوى فى الوقت المناسب. \\
\hline$\% 50.9$ & 115 & 3-بتاخد فى المبيدات الكيماوية فى الوقت المناسب. \\
\hline$\% 4$ & 9 & 4-بتصرف الدعم النقدى الخاص بتطبيق السياسة الزراعية. \\
\hline$\% 6.6$ & 15 & 5-بتاخد الوقود اللازم للعمليات الزراعية. \\
\hline$\% 8.8$ & 20 & 6-بتستخدم الكارت فى الحصول على قروض . \\
\hline$\% 10.6$ & 24 & 7-بنستخدم الكارت فى سداد السلف الزراعية. \\
\hline$\% 35.8$ & 81 & 8-بتستخدم الكارت فى تسويق المحصول. \\
\hline$\% 18.6$ & 42 & 9-بتستخدمه في نقل الملكية. \\
\hline$\% 4.4$ & 10 & 10-بنتخذمه فى الحصول على أى خدمات أخرى(ميزة، .....) \\
\hline
\end{tabular}

جدول رقم 4: مستوى إستخدام المبحوثين لكارت الفلاح الذكى

\begin{tabular}{|c|c|c|}
\hline 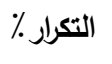 & العدد & مستوى إستخدام الكارت \\
\hline$\% 47.8$ & 108 & منخفض(من10-أقل من 17) \\
\hline$\% 52.2$ & 118 & متوسط (من17-أقل من 24) \\
\hline$\%$ & 0 & مرتفع (من24-30) \\
\hline$\% 100$ & 226 & الدجموع \\
\hline
\end{tabular}

جدول رقم 5: التوزيع العددى والتكرارى لمعرفة أوجه الإستفادة لمنظومة كارث الفلاح الذكى

\begin{tabular}{|c|c|c|c|c|c|}
\hline \multicolumn{2}{|c|}{ لا أعرف } & \multicolumn{2}{|c|}{ أعرف } & \multirow{2}{*}{ أوجه الإستفادة } & \multirow{2}{*}{ c } \\
\hline$\%$ & عدد & $\%$ & عدد & & \\
\hline 61.5 & 139 & 38.5 & 87 & والفلاح. & 1 \\
\hline 26.5 & 60 & 73.5 & 166 & يساعد فى إتخاذ القرارات الخاصة بالزراعة والفلاح. & 2 \\
\hline 20.8 & 47 & 79.2 & 179 & تطوير أسلوب الرقابة. & 3 \\
\hline
\end{tabular}


د. هالة شكري عبد الفتاح نصبير ـ.أماني سعبد عبدالحمبد الخولي

تابع جدول رقم 5: التوزيع العددى وإلتكرارى لمعرفة أوجه الإستفادة لمنظومة كارت الفلاح الأكى

\begin{tabular}{|c|c|c|c|c|c|}
\hline \multicolumn{2}{|c|}{ لا لأعرف } & \multicolumn{2}{|c|}{ أعرف } & \multirow{2}{*}{ 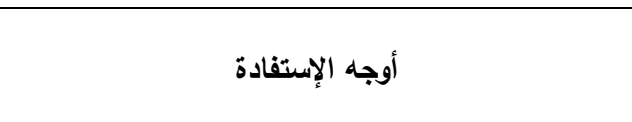 } & \multirow{2}{*}{ s } \\
\hline$\%$ & عدد & $\%$ & عدد & & \\
\hline 14.6 & 33 & 85.4 & 193 & سهولة تقديم الخدمات الزراعية. & 4 \\
\hline 41.6 & 94 & 58.4 & 132 & أقل تلفاً من الحيازة الورقية. & 5 \\
\hline 22.6 & 51 & 77.4 & 175 & يعتبر مستتد يحتوى على بيانات حيازتك الفعلية. & 6 \\
\hline 43.8 & 99 & 56.2 & 127 & توفير بعض مستلزمات الإنتاج الزراعي. & 7 \\
\hline 29.6 & 67 & 70.4 & 159 & سهولة نوزيع الأسمدة والتقاوى حسب مساحة كل حيازة. & 8 \\
\hline 24.8 & 56 & 75.2 & 170 & الزراعية. & 9 \\
\hline 87.2 & 197 & 12.8 & 29 & سلـــولة عمـل التقـارير الإحصــائية عـن المســاحات & 10 \\
\hline 96 & 217 & 4 & 9 & إمكانية التقدير المحصولى العام على مستوى الدولة. & 11 \\
\hline 6.2 & 14 & 93.8 & 212 & القضاء على الحيازات الوهمية. & 12 \\
\hline 8.4 & 19 & 91.6 & 207 & الحد من إنتشار السوق السوداء للأسددة. & 13 \\
\hline 4 & 9 & 96 & 217 & إحكام الرقابة على الجمعيات الزراعية. & 14 \\
\hline 97.8 & 221 & 2.2 & 5 & 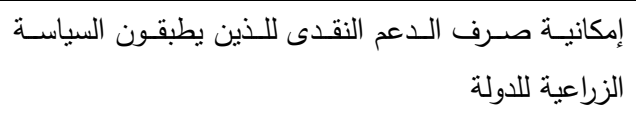 & 15 \\
\hline 6.2 & 14 & 93.8 & 212 & صرف الكيماويات المدعمة. & 16 \\
\hline 5.3 & 12 & 94.7 & 214 & سهولة الحصول على القروض بفوائد منخفة. & 17 \\
\hline 100 & 226 & 0 & 0 & سهولة سداد السلف الزراعية. & 18 \\
\hline 96.9 & 219 & 3.1 & 7 & يستخدم كبطاقة مسبقة الدفع للخدمات(ميزة). & 19 \\
\hline 93.8 & 212 & 6.2 & 14 & إمكانية تنويق المحاصيل . . & 20 \\
\hline 96.5 & 218 & 3.5 & 8 & تحديد أسعار المحاصيل. & 21 \\
\hline 1.8 & 4 & 98.2 & 222 & القضاء على تسريب الدعم للوسطاء غير المستحقين. & 22 \\
\hline 0.9 & 2 & 99.1 & 224 & يرتبط كارت الفلاح الذكى ببطاقة الرقم القومى لصاحبه. & 23 \\
\hline 100 & 226 & 0 & 0 & الصكن إدراج مشاريع أخرى من خلاله كالمعاش والتأمين & 24 \\
\hline 0.9 & 2 & 99.1 & 224 & 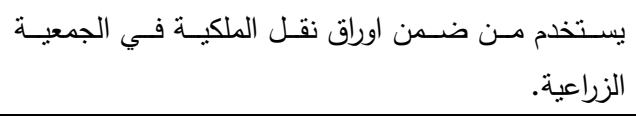 & 25 \\
\hline 100 & 226 & 0 & 0 & 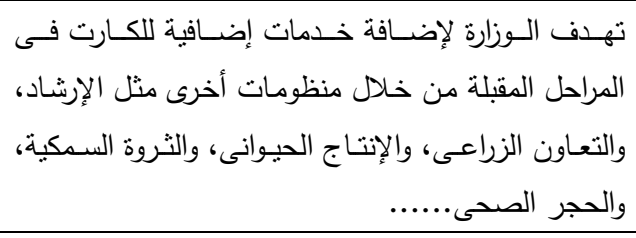 & 26 \\
\hline
\end{tabular}


جدول رقم 6: مستوى معرفة الزراع بأوجه الإستفادة لكارت الفلاح الأكى

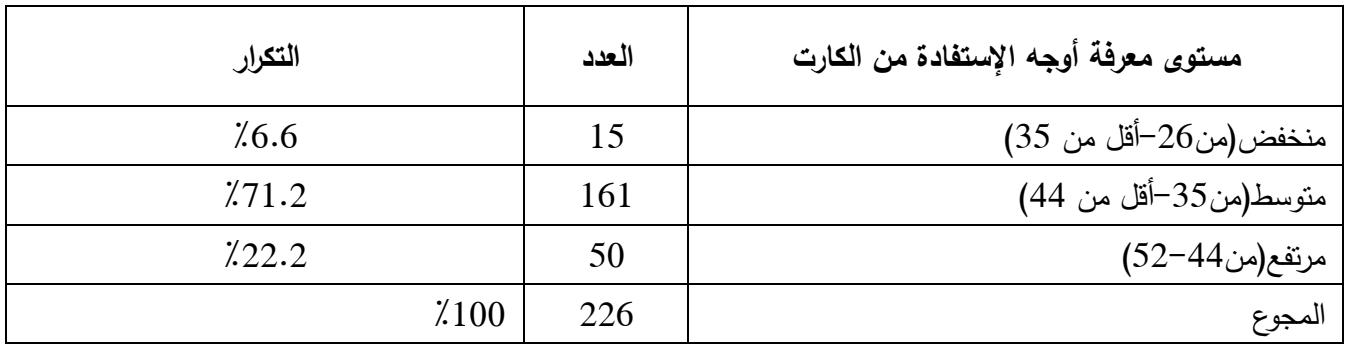

جدول رقم 7 : نتائج إختبار(ت) لمعنوية الفروق بين متوسطى درجة معرفة الزراع بأوجه الإستفادة لكارت الفلاح الأكى عند تصنيفهم على أساس النوع، المهنة الرئيسية، حيازة المشاريع الزراعية

\begin{tabular}{|c|c|c|c|c|c|c|}
\hline \multicolumn{2}{|c|}{ حيازة المشاريع الزراعية } & \multicolumn{2}{|c|}{ المهنة الرئيسية } & \multicolumn{2}{|c|}{ النوع } & \multirow{2}{*}{ إختبار (ت) } \\
\hline لا يوجد & يوجد & غير ذلك & مزارع & أنثى & ذكر & \\
\hline 42.3 & 40.7 & 42.3 & 40.6 & 40.4 & 41.6 & المتوسط حسابى \\
\hline 3.1 & 4.1 & 3.05 & 4.1 & 3.7 & 3.8 & الإنحراف معيارى \\
\hline \multicolumn{2}{|c|}{$* * 3.18$} & \multicolumn{2}{|c|}{$* * 3.37$} & \multicolumn{2}{|c|}{$* 2.07-$} & قيمة (ت) \\
\hline
\end{tabular}

جدول رقم 8: العلاقة الارتباطية بين المتغيرات المستقلة و معرفة المبحوثين بأوجه الإستفادة من كارت الفلاح الأكى

\begin{tabular}{|c|c|}
\hline معاملات الإرتباط البسيط & المتغيرات المستقلة \\
\hline 0.076 & 1-سن المبحوث \\
\hline$* * 0.327$ & 2-المستوى التعلنىى للمبحوث \\
\hline$* * 0.178-$ & 3- عدد سنوات الخبرة فى العمل الزراعى \\
\hline 0.015 & 4- الحيازة الزراعية \\
\hline 0.066 & 5-الإتجاه نحو الإرشاد \\
\hline$* * 0.251$ & 6-المرونة الذهنية \\
\hline 0.004 & 7-مستوى الطموح \\
\hline$* * 0.242$ & 8-الإتجاه نحو التغير \\
\hline
\end{tabular}


د. هالة شكري عبد الفتاح نصبير ـ.أماني سعبي عبدالحمبد الخولي

جدول رقم 9 : التوزيع العددى والنسبى للمبحوثين وفقاً لآرائهم عن أهم الطرق الإرشادية

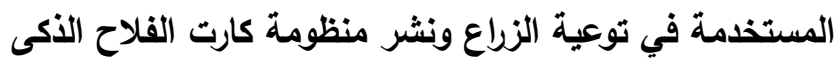

\begin{tabular}{|c|c|c|}
\hline 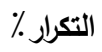 & 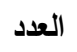 & الطرق الإرشادية \\
\hline$\% 45.6$ & 103 & 1-زيارات مكتية. \\
\hline$\% 2.2$ & 5 & 2-الإتصالات التلفونية. \\
\hline$\% 0$ & 0 & 3-الخطابات الثخصية. \\
\hline$\% 91.2$ & 206 & 4-ندوات و إجتماعات ارشادية لنشر منظومة الكارت. \\
\hline$\% 0$ & 0 & 5-ورش عمل عن منظومة الكارت. \\
\hline$\% 43.8$ & 99 & 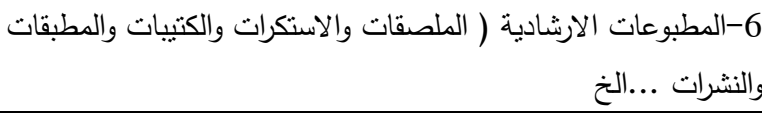 \\
\hline$\% 36.3$ & 82 & 7-البرامج الاذاعية الزراعية. \\
\hline$\% 0$ & 0 & 8-أنثطة ثقافية وعلمية إرشادية( مؤتمرات وندوات). \\
\hline$\% 36.3$ & 82 & 9-خدمات إستتشارية مقدمة في القنوات الفضائية الزراعية. \\
\hline$\% 62.4$ & 141 & 10-البرامج التليفزيونية. \\
\hline$\% 5.8$ & 13 & 11-الزيارات المنزلية و المزرعية ـ \\
\hline$\% 37.2$ & 84 & 12-المواد الارشادية في الصحف و المجلات. \\
\hline$\% 0$ & 0 & 13-الايضاح بالمشاهدة والصور المتحركة. \\
\hline$\% 0$ & 0 & 14-اسال خبيروالمنتديات.(المواقع الإلكترونية). \\
\hline$\% 37.6$ & 85 & 15-القوافل والحملات الإرشادية. \\
\hline
\end{tabular}


جدول رقم 10: التوزيع العددى والنسبى للمبحوثين وفقاً لآرائهم عن أهم معوقات استخدامهم

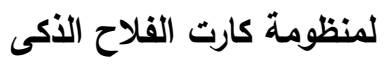

\begin{tabular}{|c|c|c|}
\hline 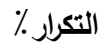 & 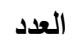 & 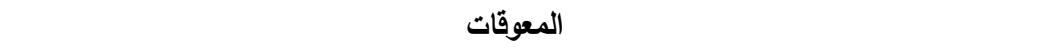 \\
\hline$\% 21.7$ & 49 & 1-وجود نسبة أمية فى المجتمع الريفى · \\
\hline$\% 83.6$ & 189 & 2-وجود نسبة أمية للحاسب الآلي · \\
\hline$\% 93.4$ & 211 & 3-ضعف إمكانيات مقارالجمعيات التعاونية الزراعية فى معظم القرى. \\
\hline$\% 44.7$ & 101 & 4-زيادة تكلفة الخدمة الإرشادية. \\
\hline$\% 95.1$ & 215 & 5-قلة عدد المرشدين الزراعينفى الجمعيات الزراعية. \\
\hline$\% 38.1$ & 86 & 6-عدم توافر أجهزة المحمول الذكة و الانترنت لدى معظم الزراع. \\
\hline$\% 74.8$ & 169 & 7- ضعف شبكة الانتزنت فى القرى . \\
\hline$\% 78.3$ & 177 & 8-كثرة اعطال أجهزة الحاسب الآلى بمقار الجمعيات التعاونية الزراعية. \\
\hline$\% 70.4$ & 159 & 9-وجود حيازات وهمية. \\
\hline$\% 85.4$ & 193 & 10-غياب الموظف المسئول عن مكنة الصرف. \\
\hline$\% 98.7$ & 223 & 11-صرف الاسمدة بالكارت محدد بمساحة معينة من حيازة الأرض. \\
\hline$\% 93.4$ & 211 & 12-المسح اللى بيقوم به المرشد بيأخر صرف الكيماوي. \\
\hline$\% 96.5$ & 218 & 13-صعوبة صرف كيماوى لبعض المحاصيل(البرسيم، الدراوة السكرية،الأرزالمخالف،البصل...) \\
\hline$\% 99.6$ & 225 & 14-صعوبة صرف كيماوى لبعض محاصيل الفاكهة(الموالح والموز ......) \\
\hline
\end{tabular}

\section{المراجع}

\section{المراجع العربية}

1- - إستراتيجية التتمية الزراعية المستدامة 2030 ، وزارة الزراعة واستصلاح الاراضى ، الجيزة

$$
2009
$$

2- الخولى، أمانى سعيد عبد الجميد، المعارف الزراعية المتوارثة، رسالة دكتوراه، كلية الزراعة،

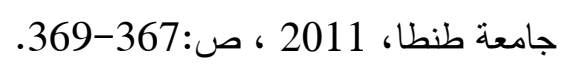

3- العبد ، عمر 2005 ، الزراعة ومجتمع المعلومات ،تعلم الانترنت مع أهم المواقع الزراعية،

دار الكتب العلمية للنشر والتوزيع ،القاهرة . 4- الربيعى، سعيد حمد 2008 : التعليم العالى فى عصر المعرفة: التغيرات والتحديات وآفاق المستقبل ، دار الثروق، عمان.

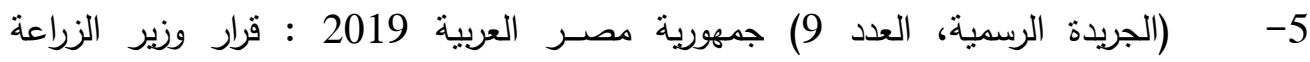

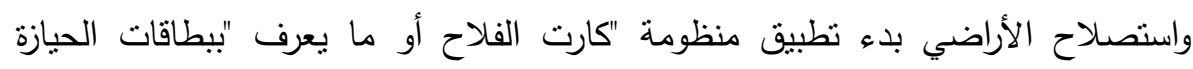

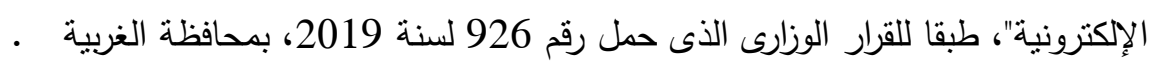




$$
\text { د. هالة شكري عبد الفتاح نصبير ـ.أماني سعبل عبدالحمبد الخولي }
$$

$$
\begin{aligned}
& \text { 6- سرحان، احمد مصطفي محمد ، ادارة المعرفة الزراعية وعلاقاتها بمعدلات الاداء الوظيفي، } \\
& \text { دراسة حالة على الجهاز الارشادي الزراعي بمحافظة قنا- مصر ، مجلة جامعة المنصورة }
\end{aligned}
$$

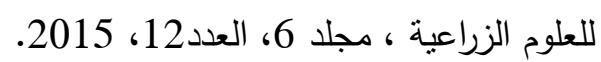

$$
\begin{aligned}
& \text { 7- عبد الواحد ، احمد محمد حفنى ، دراسة مستقبلية للارشاد الزراعي الالكتروني في مصر، } \\
& \text { رسالة دكتوراة ، قسم الارشاد الزراعي والمجتمع الريفي ، جامعة اسيوط، 2007. } \\
& \text { 8- مديرية الزراعة بالغربية، مركز المعلومات ودعم لإتخاذ القرار، } 2019 . \\
& \text { 9- ملوك ، محمد مجدى ، زياد عبداله محمد هشال ، "المعوقات التى تواجه تكنولوجيا } \\
& \text { المعلومات والإتصالات من وجهة نظر العاملين فى الإدارة المركزية للإزشاد الزراعى" ، كلى ، } \\
& \text { مجلة الإسكندرية للتبادل العلمى ، مجلد 37، العدد3، يوليو سبتمبر } 2016 .
\end{aligned}
$$

\section{*English reference}

1- Chapman ,R.and tom S. 2009 ,ICTs and rural Development : review of the literature, current interventions and opportunities for action ,overseas level

2 - FAO, 2001, Farm Net, Farmer information network for agricult ural and rural development, SDR, WAICENT (On Line). http://ftp. fao.org/sd/farmnet.pdf

3 - Okeke, Mn,Nwalieji H U , Uzuegbunam C.O"Emerging Role of information communication technologies in extension service delivery in Nigeria : A review " jornal of agricultural extension , vol,19(1) JUNE , 2015.

4 - Suvedi, Murari, Michael kaplowitz, "CORE COMPETENCY HANDBOOK " Department of community sustainability ,Michigan state university . East Lansing, Michigan, USA, February 2016.

5 - Zazueta, F2003, use of hand held computers in agricultural extension programs. (Online).

https://www.youm7.com/Tags/Index?id=379864\&tag

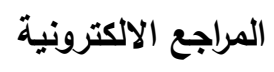




\title{
Using Farmer the smart card in some villages of Gharbia Governorate Agricultural Extension and Rural Development Research institute \\ Hala Shokry Abd-Elfatah Amany Said Elkholy \\ Agricultural Extension Research and Rural Development Institute \\ Agricultural Research Center
}

\begin{abstract}
The research aimed to identify the reality and level of using the smart farmer card system, the level of farmers 'knowledge of ways to benefit from it, determining the relationship between the independent studied variables and the degree of farmers' knowledge of aspects of benefit from using the smart farmer card, identifying the most important indicative methods which using to awareness farmers and publishing the smart farmer card system.

The sample was collected from (226) respondents selected randomly from the farmers' four villages in Gharbia Governorate; the data were collected using a questionnaire by personal interview during November 2020 .

Frequencies, percentages, arithmetic mean standard deviation, Alpha coefficient, Means, simple correlation "Pearson", multiple linear regressions, and "T-test" to display and analyze data.

The research reached the following results

1-The results showed that nearly three-quarters of the respondents and less take their share of seeds, fertilizers and chemical pesticides on the right time, used the smart farmer's card in selling crops and transferring agricultural ownership, While other uses were not really applied. The level of using smart farmer card was medium and low.
\end{abstract}




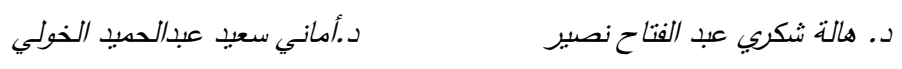

2- There were significant differences between farmers' knowledge of the benefits from using the smart farmer card degree of respondents grouped according to sax, main work, and ownership of agricultural projects.

3- There is a significant positive correlation between degree of farmers 'knowledge of benefiting from the smart farmer's card and each of years of education, Mind flexibility, and trend towards change. There is a negative correlation with the number of years of experience in agricultural work.

4- The respondents confirmed that seminars and extension meeting $(91.2 \%)$, television programs $(62,4 \%)$, office visits, informative publication $(45,6 \%)$, convoys and extension campaigns, informative materials in newspapers and magazines, advisory services provided in agricultural satellite channels, and agricultural radio programs are the most important extension methods that used from awareness farmers and publishing the smart farmer card system.

5-Results showed(83,6 \%) that: difficulty of having chemical manure for some crops and fruit crops, limited of agricultural area, a few Agricultural extension agents, weak capabilities of agricultural societies, absence of the employee Responsible for the exchange machine, delay in chemical manure, computer illiteracy, weak internet, frequent computer malfunctions and fake holdings, were the most important obstacles facing the smart farmer's card system.

6- It's necessary to provide more than one exchange machine for agricultural supplies, strengthening mobile networks and the Internet, providing computers, and facilitating of getting smart farmer card. 